\title{
Scoping review on vector-borne diseases in urban areas: transmission dynamics, vectorial capacity and co-infection
}

\author{
Marcus Eder ${ }^{1,2}$, Fanny Cortes ${ }^{3}$, Noêmia Teixeira de Siqueira Filha ${ }^{4}$, Giovanny Vinícius Araújo de França ${ }^{5}$, \\ Stéphanie Degroote ${ }^{6}$, Cynthia Braga ${ }^{2}$, Valéry Ridde ${ }^{6,7}$ and Celina Maria Turchi Martelli ${ }^{2 *}$
}

\begin{abstract}
Background: Transmission dynamics, vectorial capacity, and co-infections have substantial impacts on vector-borne diseases (VBDs) affecting urban and suburban populations. Reviewing key factors can provide insight into priority research areas and offer suggestions for potential interventions.

Main body: Through a scoping review, we identify knowledge gaps on transmission dynamics, vectorial capacity, and co-infections regarding VBDs in urban areas. Peer-reviewed and grey literature published between 2000 and 2016 was searched. We screened abstracts and full texts to select studies. Using an extraction grid, we retrieved general data, results, lessons learned and recommendations, future research avenues, and practice implications. We classified studies by VBD and country/continent and identified relevant knowledge gaps. Of 773 articles selected for full-text screening, 50 were included in the review: 23 based on research in the Americas, 15 in Asia, 10 in Africa, and one each in Europe and Australia. The largest body of evidence concerning VBD epidemiology in urban areas concerned dengue and malaria. Other arboviruses covered included chikungunya and West Nile virus, other parasitic diseases such as leishmaniasis and trypanosomiasis, and bacterial rickettsiosis and plague. Most articles retrieved in our review combined transmission dynamics and vectorial capacity; only two combined transmission dynamics and co-infection. The review identified significant knowledge gaps on the role of asymptomatic individuals, the effects of co-infection and other host factors, and the impacts of climatic, environmental, and socioeconomic factors on VBD transmission in urban areas. Limitations included the trade-off from narrowing the search strategy (missing out on classical modelling studies), a lack of studies on co-infections, most studies being only descriptive, and few offering concrete public health recommendations. More research is needed on transmission risk in homes and workplaces, given increasingly dynamic and mobile populations. The lack of studies on co-infection hampers monitoring of infections transmitted by the same vector.
\end{abstract}

Conclusions: Strengthening VBD surveillance and control, particularly in asymptomatic cases and mobile populations, as well as using early warning tools to predict increasing transmission, were key strategies identified for public health policy and practice.

Keywords: Arboviruses, Disease vectors, Coinfection, Urban population, Epidemiology, Review

\footnotetext{
* Correspondence: turchicm@gmail.com

${ }^{2}$ Aggeu Magalhaes Institute (IAM) / Oswaldo Cruz Foundation (Fiocruz),

Avenida Professor Moraes Rego, s/n. Cidade Universitaria. CEP 50, Recife,

Pernambuco 740-465, Brazil

Full list of author information is available at the end of the article
}

(c) The Author(s). 2018 Open Access This article is distributed under the terms of the Creative Commons Attribution 4.0 International License (http://creativecommons.org/licenses/by/4.0/), which permits unrestricted use, distribution, and reproduction in any medium, provided you give appropriate credit to the original author(s) and the source, provide a link to the Creative Commons license, and indicate if changes were made. The Creative Commons Public Domain Dedication waiver (http://creativecommons.org/publicdomain/zero/1.0/) applies to the data made available in this article, unless otherwise stated. 


\section{Multilingual abstracts}

Please see Additional file 1 for translations of the abstract into the six official working languages of the United Nations.

\section{Background}

According to the World Health Organization (WHO), vector-borne diseases (VBDs) account for more than $17 \%$ of all infectious diseases and cause more than 1 million deaths annually [1]. Vector-borne diseases are transmitted from person to person via a competent vector, such as mosquitoes, midges and flies.

Transmission dynamics describes a range of factors influencing how effectively transmission occurs over space and time, and in a specific population. These factors include basic reproduction number, host immunity, travel and human behaviour. Transmission dynamics are determined by the interaction between pathogen, vector, host (human, and in many cases also other animals, serving as reservoir or amplifier) and other environmental factors [2].

Vectorial capacity refers to the ability of a mosquito population's to transmit the pathogen to a new susceptible population [3].

The term co-infection describes human infection through more than one organism, either by different strains of the same (e.g. two genetically different falciparum malaria protozoa), or entirely different pathogens (e.g. falciparum malaria protozoa and intestinal helminths). Here, also co-circulation is considered, when more than one different pathogens are present in an insect vector (e.g. in mosquito populations of a specific region) [4].

Malaria is a VBD that caused over 400000 deaths in 2015, most of them in children under 5 years of age [5]. Traditionally associated with rural transmission, malaria is increasing found in urban and peri-urban areas $[6,7]$. An entomological marker of malaria transmission is the entomological inoculation rate (EIR). It describes the number of infected bites per unit of time, and a function of the so-called 'man biting rate' (MBR, the number of bites per person per time unit) and the sporozoite rate (rate of infected mosquitoes, i.e. those carrying malaria parasites ready to infect humans).

Currently dengue, a virus transmitted through Aedes mosquitoes, threatens a half-billion people globally [8]. Unlike yellow fever, where sylvatic (forest) mosquito species and non-human primate reservoirs play a critical role in the transmission, dengue only requires humans, a fact that explains its rapid spread in populated urban areas [9]. Dengue incidence has increased dramatically in the Americas, and recent introductions of chikungunya and Zika have resulted in serious epidemics in these regions $[10,11]$. Other VBDs, such as American trypanosomiasis (Chagas disease), leishmaniasis, and filariasis, have affected hundreds of millions of people globally [12].

Approximately half of the world's population currently live in cities. The United Nations projects that 2.5 billion people will be added to the urban population by 2050 , mostly on the Asian and African continents [13]. This rapid and increasing urbanization has posed a great challenge to nations, especially those less developed [14]. Urbanization has had an impact on the epidemiological pattern of infectious diseases. The main factors are urban sprawl into forested areas, overcrowding, and precarious urban infrastructures and housing in urban areas of developing countries. The absence of necessary investments in infrastructure in these countries poses a serious threat to human health, including the (re-)emergence and adaptation of infectious agents in urban areas such as dengue in South East Asia or, Chagas in Latin America in areas where poor housing is hindering effective vector control [14-16].

Basic knowledge about VBD transmission includes population susceptibility, vectorial capacity, and interaction of infectious agents. The understanding of VBD transmission and persistence is essential for establishing effective prevention and control interventions. Of similar importance is to know key aspects of introduction, maintenance, and spread of VBDs, as well as the role of environmental and climate factors, the urbanization process, socioeconomic conditions, population dynamics and mobility [2, 17-20].

This scoping review evaluated the current state of knowledge on transmission dynamics, vectorial capacity, and co-infection regarding VBDs in urban areas from 2000 to 2016, to identify research gaps and implications for public health policy and practice.

\section{Main text \\ Research question}

We conducted a scoping review adapting Arksey and O'Malley's [21] methodological framework. A three-round eDelphi survey was used to select six topics considered highest priority by a panel of 109 international VBD experts, the majority of them being from Brazil, Burkina Faso, Canada, Colombia, France, Spain and the United States of America (43\% researchers; $52 \%$ public health decision-makers; $5 \%$ from the private sector). The three rounds were: 1) suggestions of research topics; 2) ranking of topics identified (more than 80 topics, rated from "1-eliminate" to "5-top priority"); and 3) final selection of highest-priority topics (the 20 subjects rated 4 or 5 by more than $65 \%$ of the participants). By the end of the third round, the present topic-the impact of transmission dynamics, vectorial capacity, and co-infections on the burden of vector-borne diseases in urban areas- 
had obtained the mean rating of $3.90 \pm 0.92$ and was ranked fourth. It was therefore among six top rated topics taken forward for research carried out by the consortium groups.

\section{Search strategy}

We used the following key concepts: ["transmission dynamics" OR "vectorial capacity" OR "co-infection"] AND "vector-borne" AND "urban areas" AND "epidemiology". All possible word variations and MeSH terms (as appropriate) were added to the search command and validated by a librarian (see Additional file 2) for the following databases: PubMed, Embase, Global Health, Cochrane Database of Systematic Reviews, OpenGrey, the Grey Literature Report, and WHOLIS. Additional articles were identified by screening the references of papers that met our inclusion criteria. As part of the protocol development the consortium members considered the 2014 World Urbanization Prospects issued by the Population Division of UNDESA [13].

The literature search was undertaken from August to September 2016. We used Mendeley and Endnote software to manage references and remove duplicates.

\section{Inclusion and exclusion criteria}

We included all articles and reports published in peer-reviewed journals or grey literature written in English, French, Portuguese, Spanish, German, or Italian and published between 2000 and 2016. We excluded: articles focused on clinical or laboratory characteristics, vector prevalence or seroprevalence only; reviews; conference papers; articles without research data; articles not addressing human disease; articles reporting water-borne diseases or diseases without insect vector; studies conducted in rural areas; and interventional studies, such as mass drug administration, intermittent preventive treatment, and vector control programs.

\section{Study selection}

We performed a pilot round of study selection to evaluate consistency in the application of the above criteria and discuss discrepancies with 20 randomly selected references. For both abstract and full-text screening, two independent reviewers (FC and NTSF) selected the studies through the title and abstract/full-text, and a third reviewer (ME) resolved discordances.

After completing full-text screening for 205 articles, an additional step was introduced to retain references that combined at least two elements of the search strategy: transmission dynamics and vectorial capacity or transmission dynamics and co-infection. This last step was done manually by the reviewers.

\section{Data extraction, summary, and analysis}

An extraction grid was created allowing to record for each of the selected studies the following information: general information, key objectives and methods; overview of results; methodological limitations and challenges encountered in lessons learnt/recommendations; future research avenues; and, public health policy or practice implications. Similarly, the methodological and quality aspects of each study were evaluated using the modified Mixed Methods Appraisal Tool (MMAT; for description of qualitative, quantitative, and mixed methods studies) [22] and parts of the TIDieR (Template for Intervention Description and Replication) checklist [23]. Summary tables and graphs were produced. Initially, the three contributors (FC, ME, NTSF) independently extracted data from the same five articles, to ensure harmonization. Any remaining difficulties were resolved in a discussion with the remaining two participants. Subsequently, the remaining 45 articles were summarised with quality assessed by the same three contributors and results recorded in the extraction grid.

\section{Results}

Description of included studies and their funding sources

The search strategy initially identified 9239 records. After removing duplicates and articles published before 2000, we screened 3365 articles by title and abstract and retrieved 773 of them. After full-text screening, 50 articles were selected for the scoping review (Preferred Reporting Items for Systematic Reviews and Meta-Analyses [PRISMA] flowchart, Fig. 1).

Most of the 50 studies retained were conducted in the Americas $(n=23 ; 46 \%)$, followed by Asia $(n=15$; $30 \%)$, Africa $(n=10 ; 20 \%)$, Europe $(n=1 ; 2 \%)$ and Australia $(n=1 ; 2 \%)$ (continents, Table 1 ; countries, Additional file 3; map, Fig. 2). Selected articles were organized into three groups of diseases: 1$)$ dengue $(n=20$; $40 \%), 2)$ malaria $(n=15 ; 30 \%)$, and 3$)$ others $(n=15$; $30 \%)$, which included parasitic diseases: leishmaniasis $(n=4)$ and Chagas disease $(n=2)$; other arboviruses: chikungunya $(n=2)$, West Nile virus $(n=2)$, yellow fever $(n=2)$, and Ross River virus $(n=1)$; and two bacterial diseases: plague $(n=1)$ and rickettsiosis $(n=1)$ (Table 1$)$. Two studies reported on co-infections, one on multiple Plamodium falciparum strains, the other on combined malaria, helminth, and human immunodeficiency virus (HIV) infection in pregnant women. Studies are summarized in Table 2.

Studies were funded mostly through national $(n=21$; $41 \%)$ and international $(n=15 ; 29 \%)$ government sources, followed by universities, non-government organizations, and global funding sources $(<10 \%$ each). Only one study was funded through pharmaceutical companies, but did not involve clinical trials (hence 


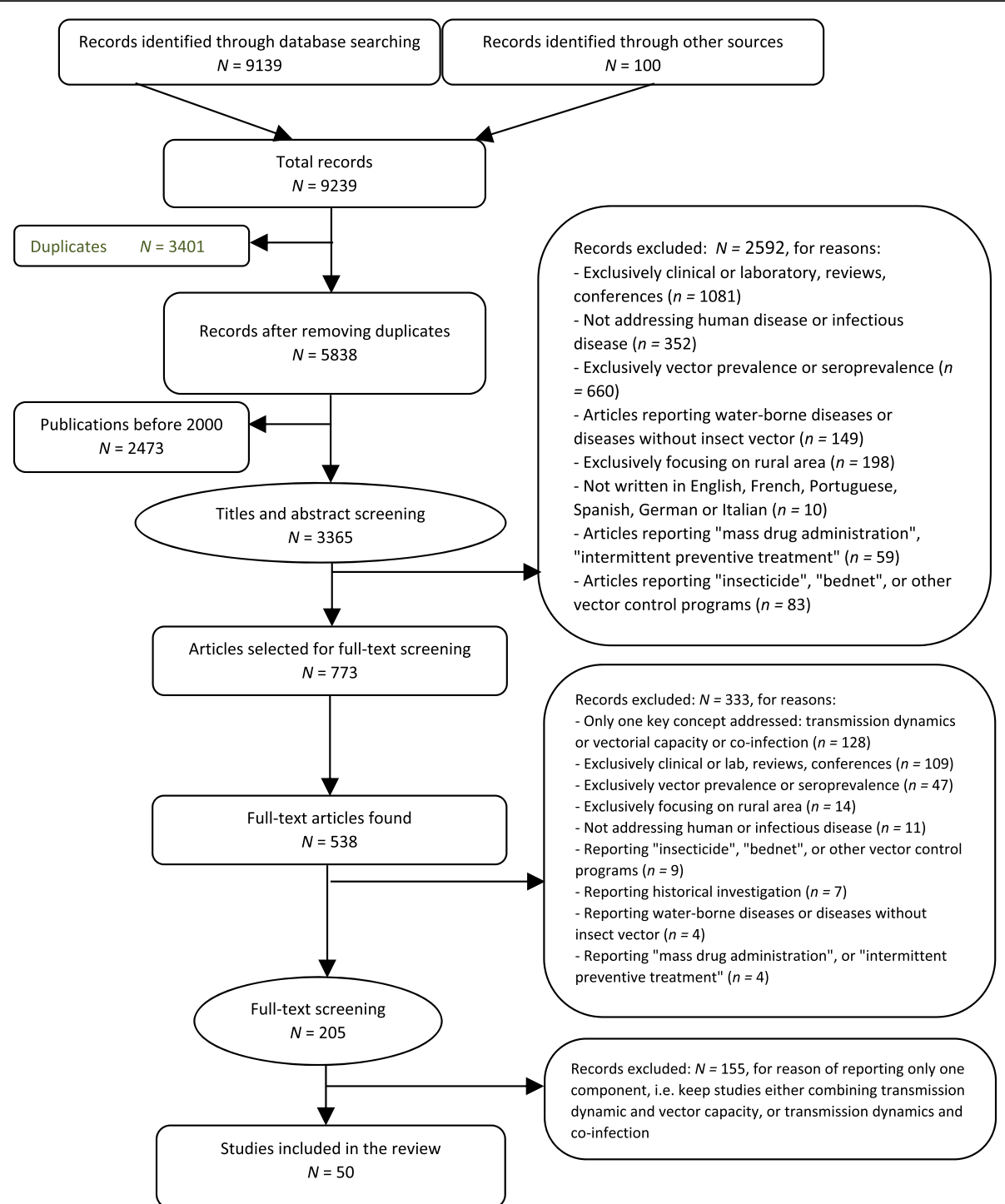

Fig. 1 Prisma Chart showing references retrieved at different stages of the search (full text review)

was not excluded); some studies had several funding sources (Fig. 3).

We transferred information for the 50 included studies into an extraction grid. All studies were descriptive. An overview of study methods employed in each disease group shows that nearly half of the studies on dengue used either spatial (30\%) or dynamic (15\%) modeling, followed by one third ( $20 \%$ and $13 \%$, respectively) on studies on malaria.. The remainder of malaria research included mostly cross-sectional $(n=4 ; 27 \%)$ and cohort

Table 1 Final selection of $N=50$ references: Group of diseases: dengue, malaria and others (ordered by parasitic, viral and bacterial diseases) by continent

\begin{tabular}{|c|c|c|c|c|c|c|c|c|c|c|c|}
\hline Continent & Dengue & Malaria & Leishmaniasis & Chagas disease & West Nile & Chikungunya & Yellow fever & Ross River virus & Plague & Rickettsiae & Total \\
\hline Americas & 12 & 2 & 3 & 2 & 2 & 0 & 1 & 0 & 0 & 1 & 23 \\
\hline Europe & 0 & 0 & 0 & 0 & 0 & 1 & 0 & 0 & 0 & 0 & 1 \\
\hline Africa & 1 & 8 & 0 & 0 & 0 & 0 & 1 & 0 & 0 & 0 & 10 \\
\hline Asia & 7 & 5 & 1 & 0 & 0 & 1 & 0 & 0 & 1 & 0 & 15 \\
\hline Australia & 0 & 0 & 0 & 0 & 0 & 0 & 0 & 1 & 0 & 0 & 1 \\
\hline Total & 20 & 15 & 4 & 2 & 2 & 2 & 2 & 1 & 1 & 1 & 50 \\
\hline
\end{tabular}




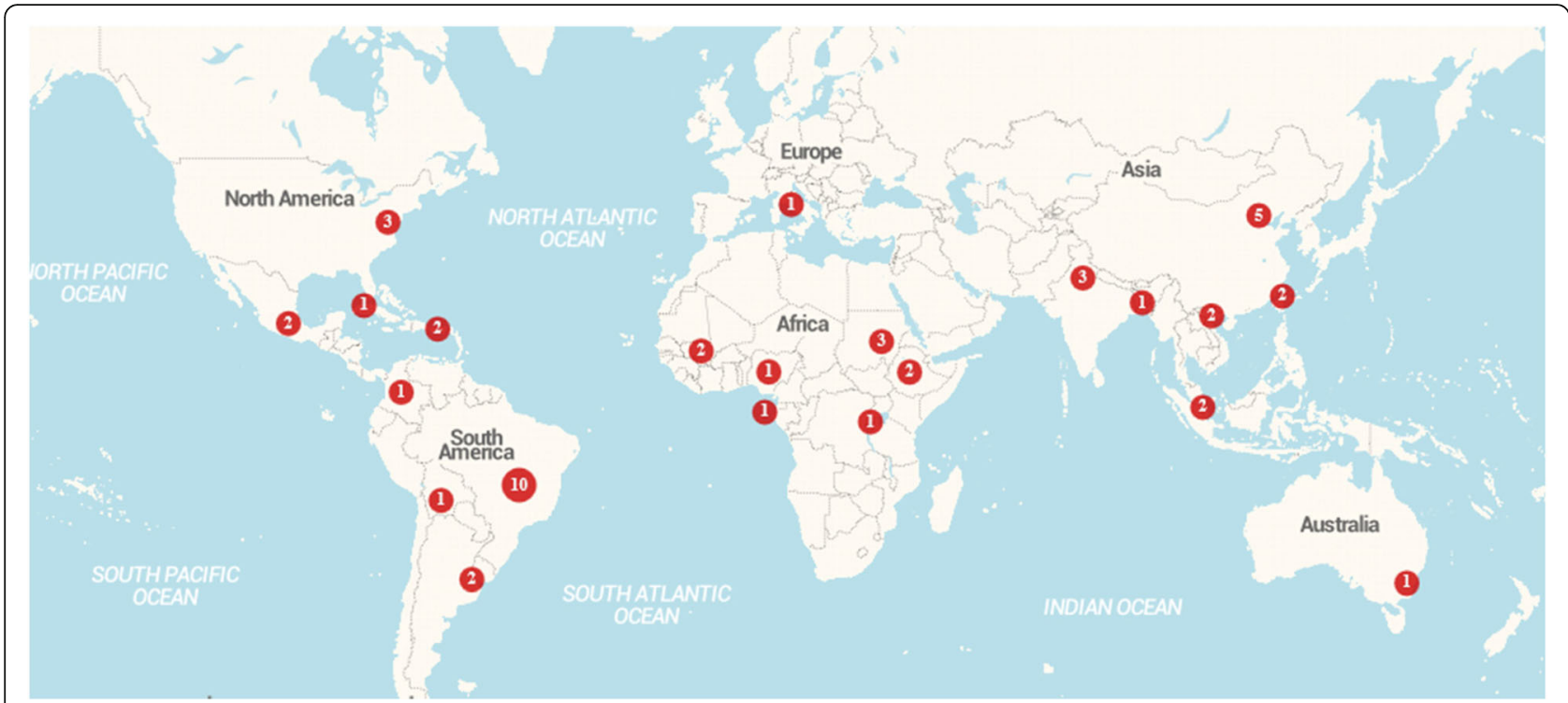

Fig. 2 Distribution of final selection of $N=50$ references by geographic regions

studies $(n=6 ; 40 \%)$. Studies on other pathogens were mostly outbreak $(n=7 ; 47 \%)$ and other case-control $(n=3 ; 20 \%)$ studies (Table 3$)$.

We applied the MMAT to evaluate study quality [22]. All studies had clear objectives set out, which were addressed in $90 \%(n=18)$ of dengue studies and $87 \%(n=13)$ of studies on other VBDs. Relevant sampling strategy for studying human or vector characteristics was present in approximately $65 \%$ of studies on dengue and other pathogens, but to a lesser degree $(n=4,27 \%)$ in malaria work. Representation of the population under study was also better addressed in studies on dengue and other pathogens (around 70\%) than in malaria studies $(n=6 ; 40 \%)$. Appropriate measurement was captured well in both dengue and malaria studies ( $n=17,85 \%$ and, $n=13 ; 87 \%$, respectively). Response rate (where appropriate) was clearly reported only in about $25 \%$ of dengue studies and even less in other work (Fig. 4). Given the absence of any intervention studies, the TIDieR tool was only applicable to very limited aspects of the included studies. Due to the limited added benefit, it was therefore agreed to not consider TIDieR further in the extraction.

\section{Description of findings of the scoping review Dengue transmission dynamics and vectorial capacity studies}

Dengue research was identified mostly in the Americas and Asia. The majority of the studies $(n=17)$ evaluated the relationship between the incidence of dengue cases and vector density in endemic areas, and/or mobility of the human population. A large number of studies also addressed asymptomatic infection as a factor related to the spread of dengue virus infection, the climatic variation in relation to vector abundance, and the role of socioeconomic conditions. The role of imported dengue fever cases in triggering outbreaks in non-endemic cities was highlighted [24]. Human movement due to economic development and/or tourism was considered a determinant for the spread of dengue infection [24-26].

\section{Incidence of dengue cases or dengue virus infection}

The heterogeneity of dengue transmission in inner cities seemed to be a common feature of the studies. Population immunity and asymptomatic infection play an important role in dengue transmission dynamics, resulting in higher incidence of dengue infection in previously lower prevalence areas [25]. Also, the intensity of transmission in highly urbanized settings may not be perceived as an epidemic due to asymptomatic infection, suggesting the occurrence of a "silent epidemic", as shown in Salvador city, Brazil (2008-2009) [25]. Another prospective study demonstrated that dengue infection in the community was mainly spread by asymptomatic adults [27]. In concordance with these studies, asymptomatic dengue cases were also a potential source of subsequent outbreaks, as seen in four cities of Valle del Cauca, Colombia [26]. A study conducted in Ho Chi Minh city, Vietnam, provided evidence for some household dengue risk clustering, but on a short temporal scale rather than as sustained chains of localized transmission [28]. These findings are important for surveillance and control strategies [25-27].

\section{Mobility of human populations as a source of outbreaks and/or disease persistence}

The study conducted in Mexico City (2011-2012) pointed out that, besides asymptomatic individuals, human mobility 


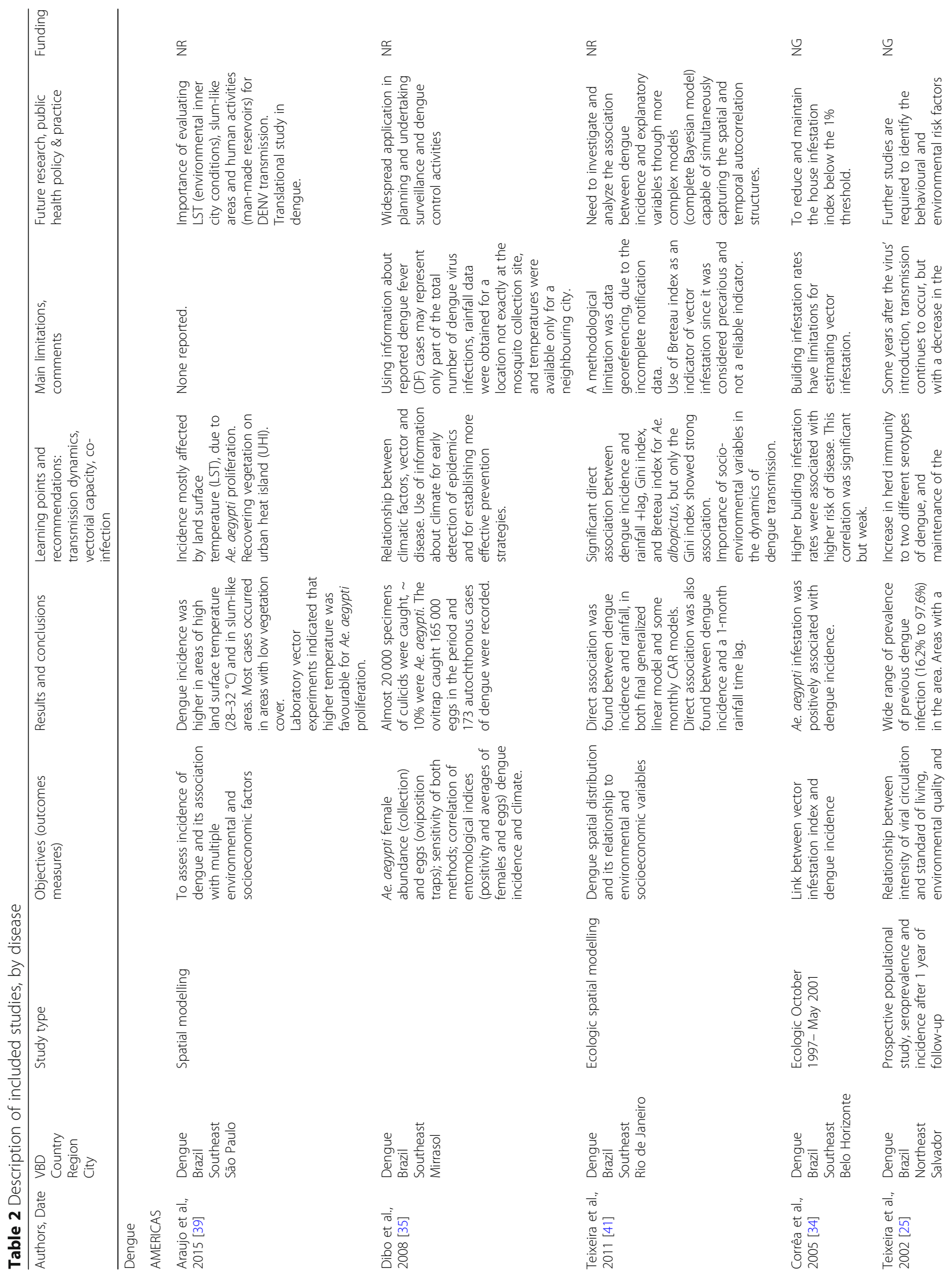




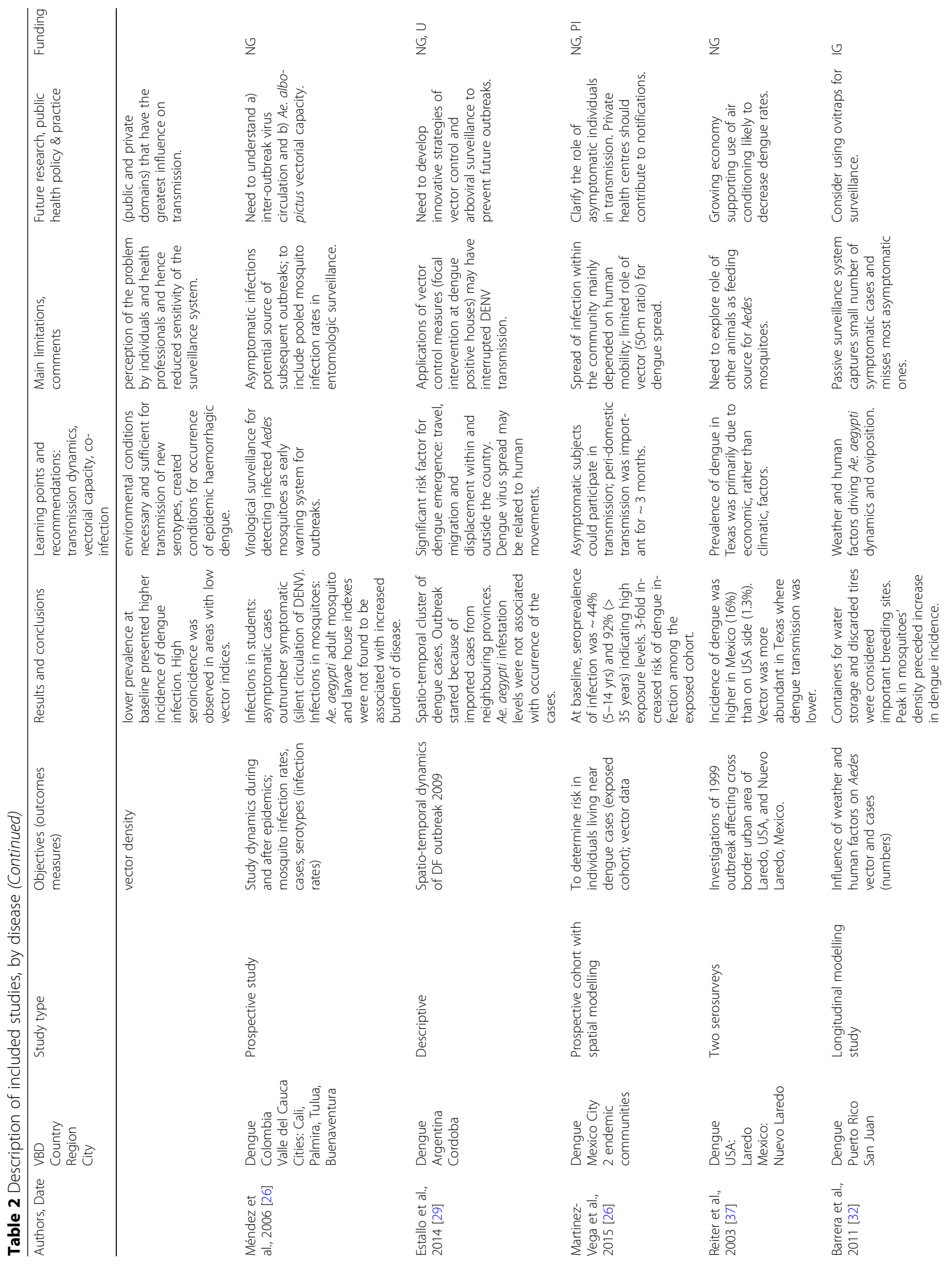




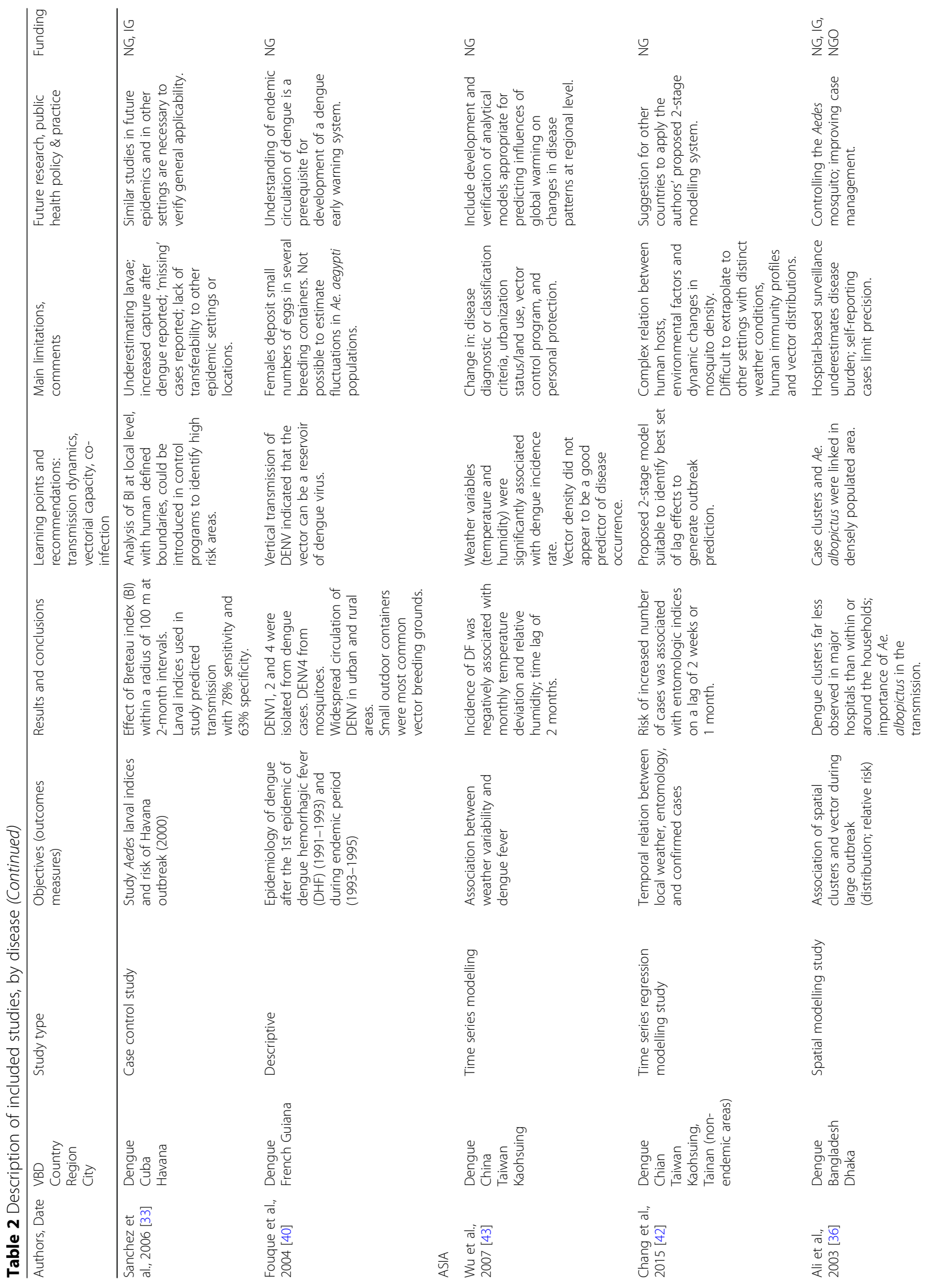




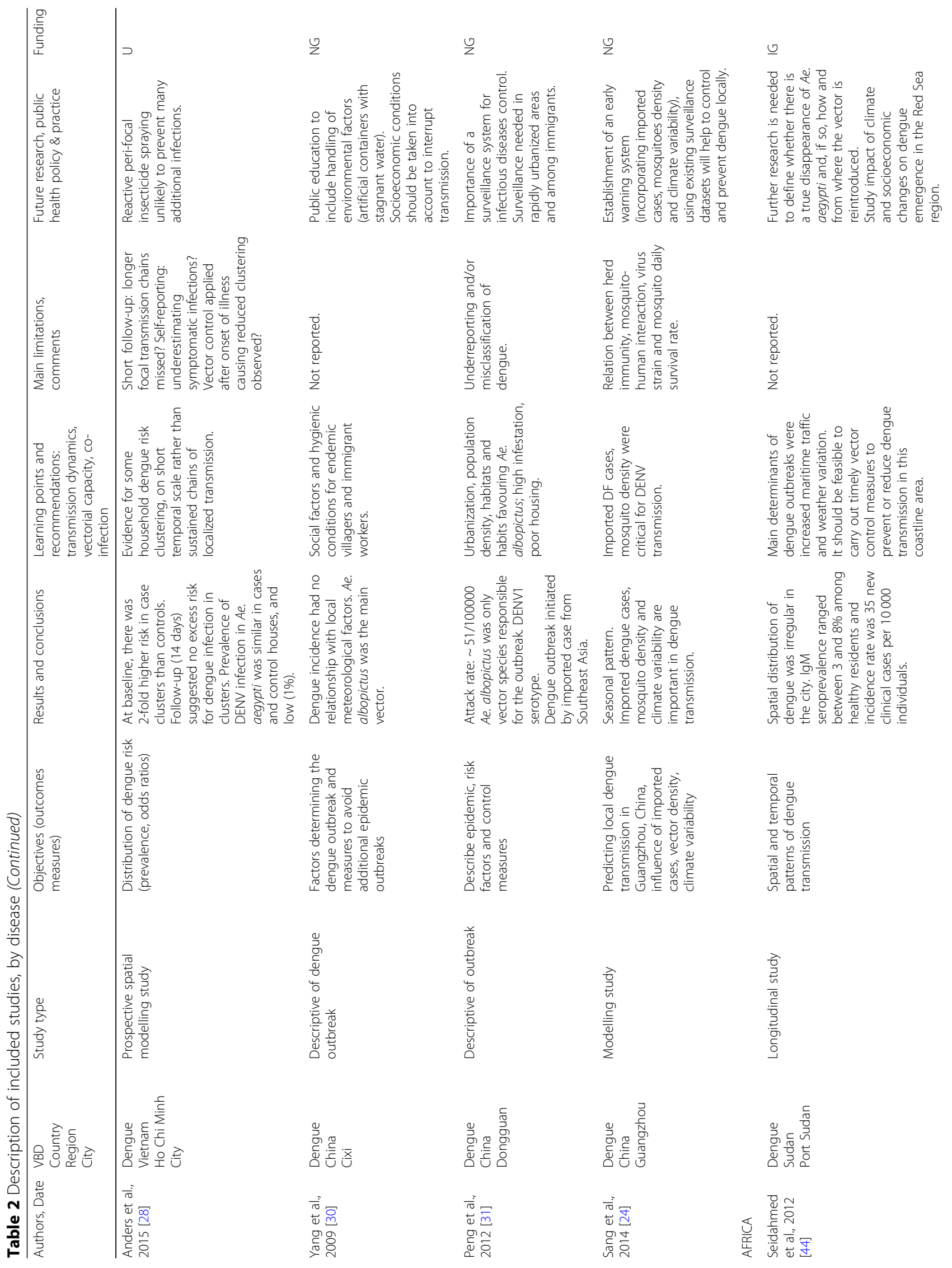




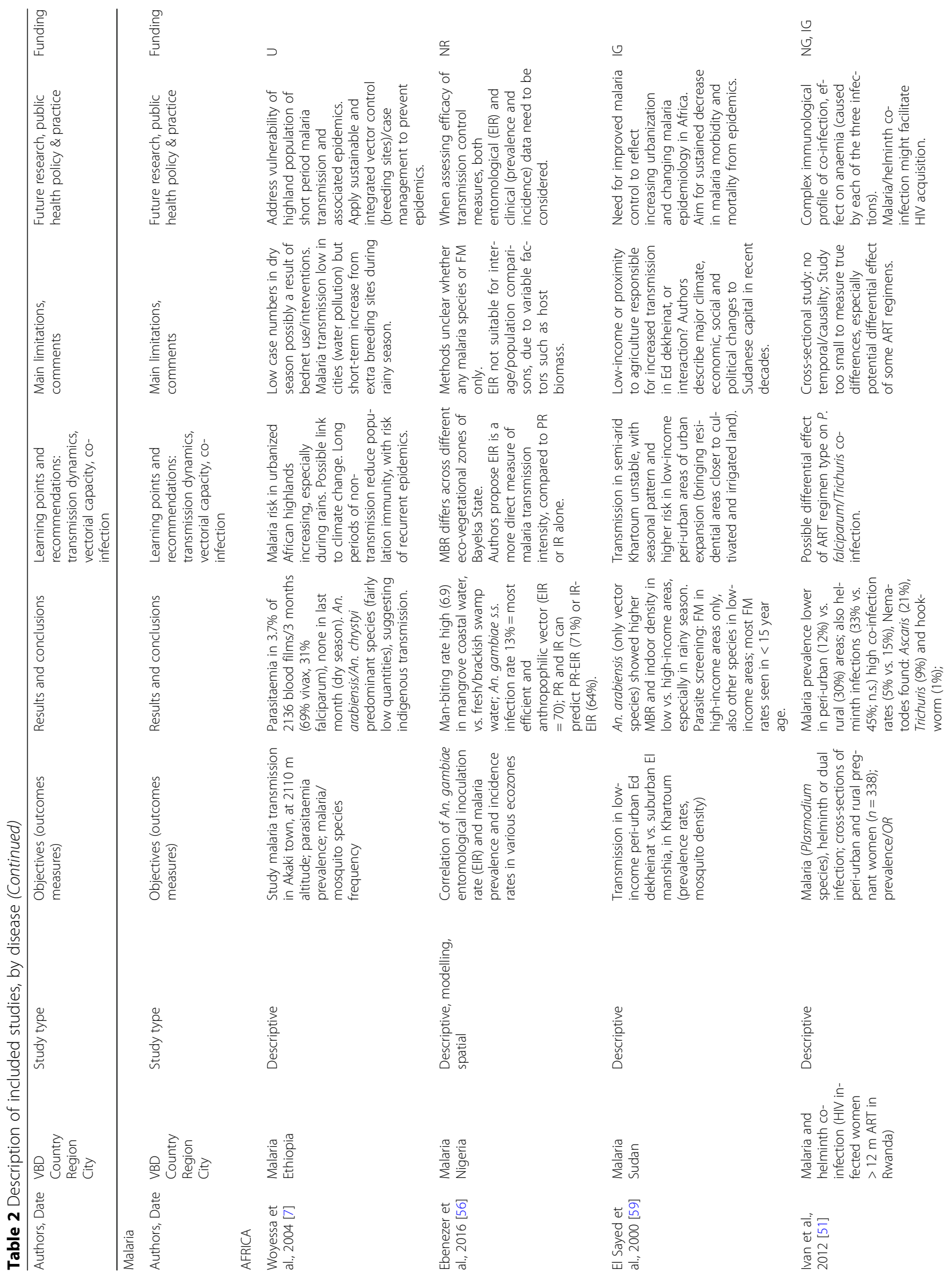




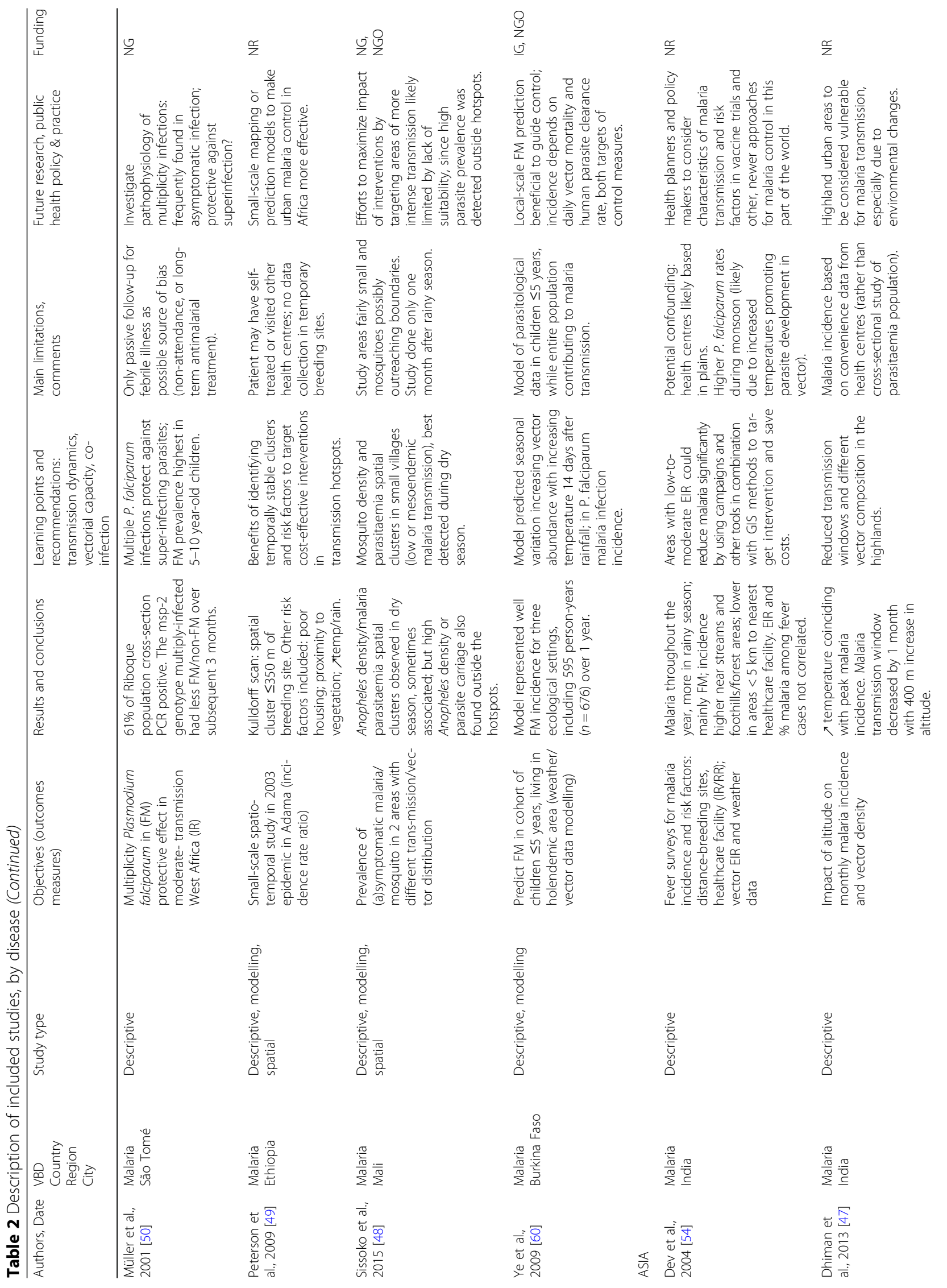




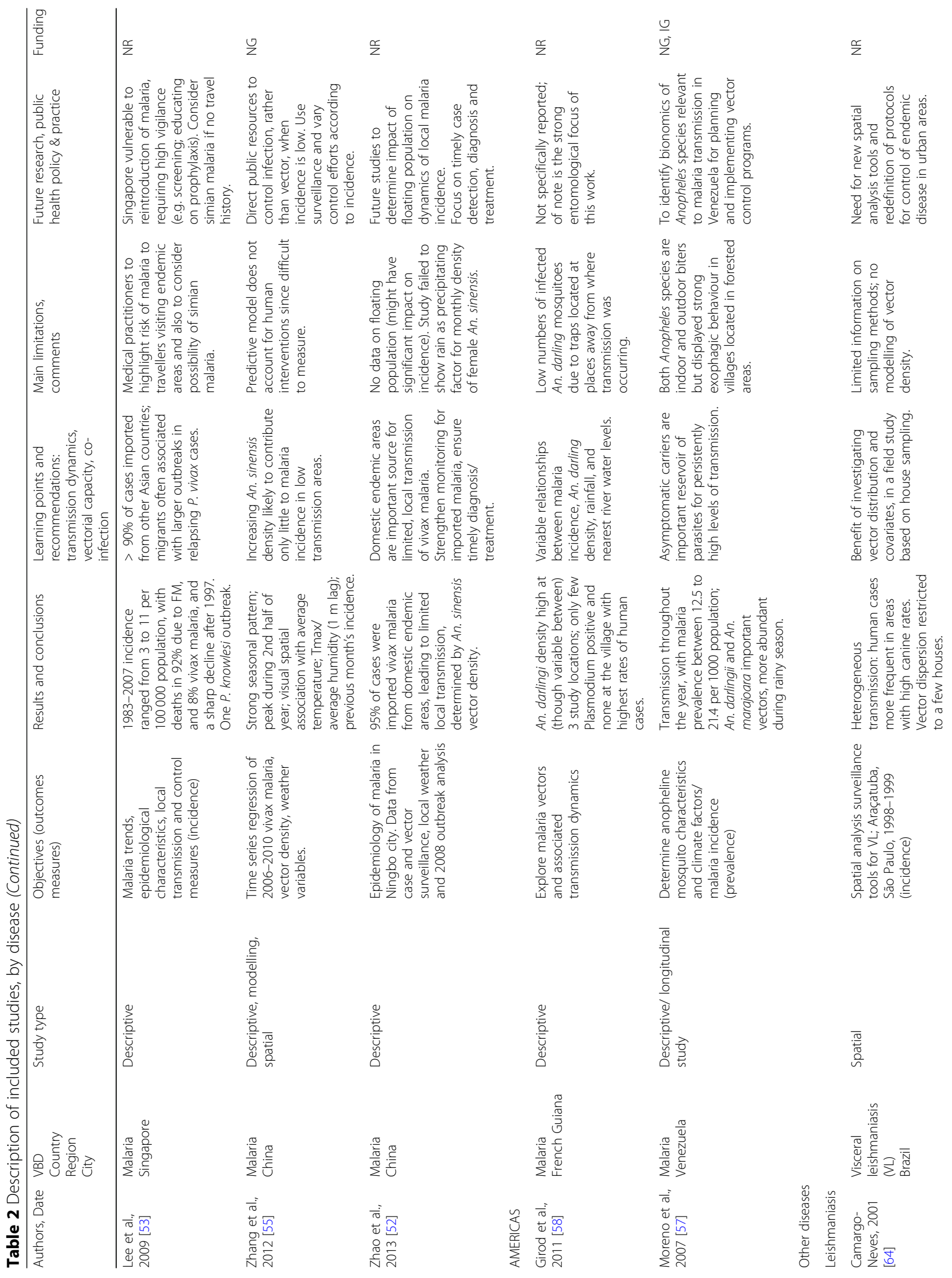




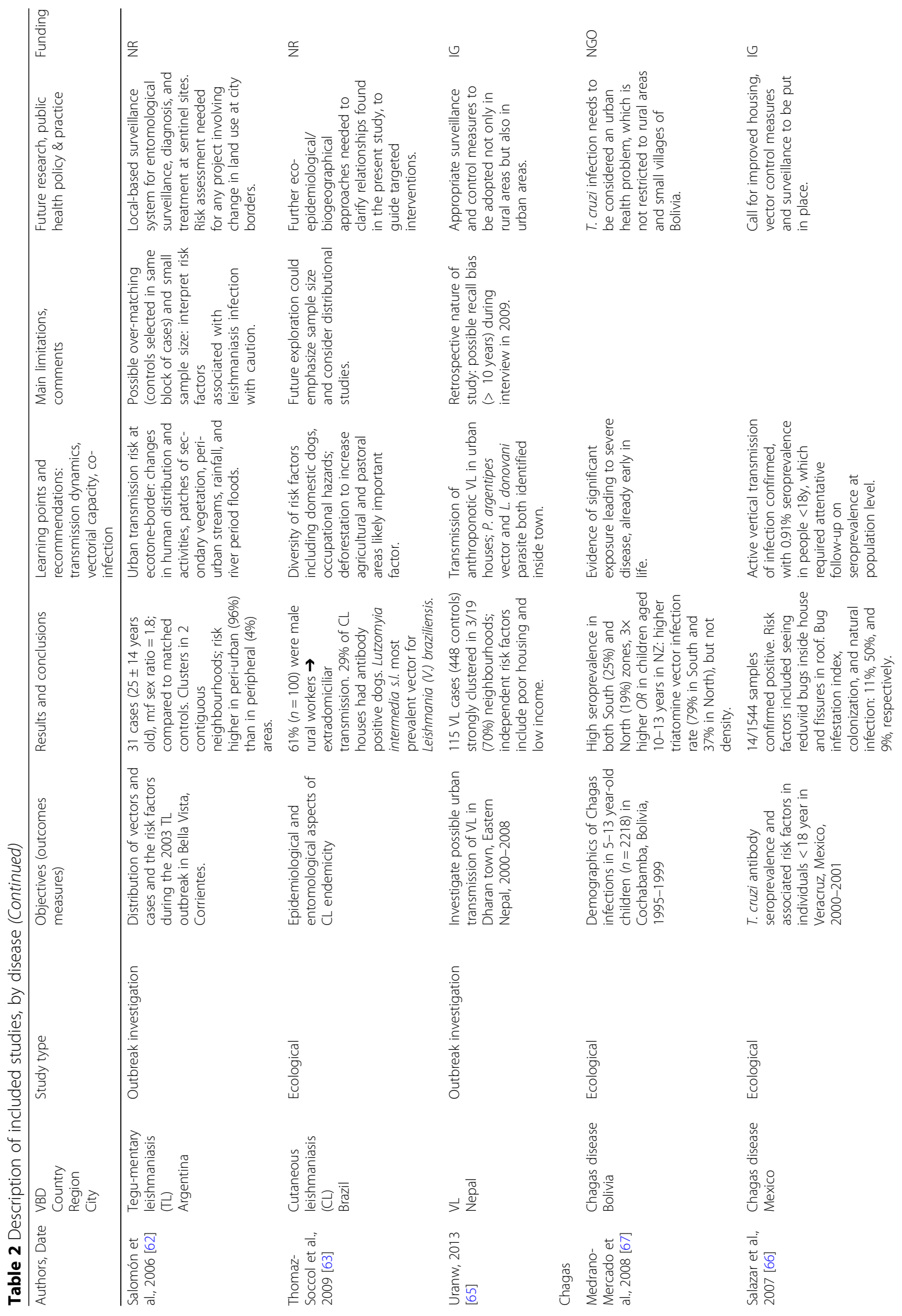




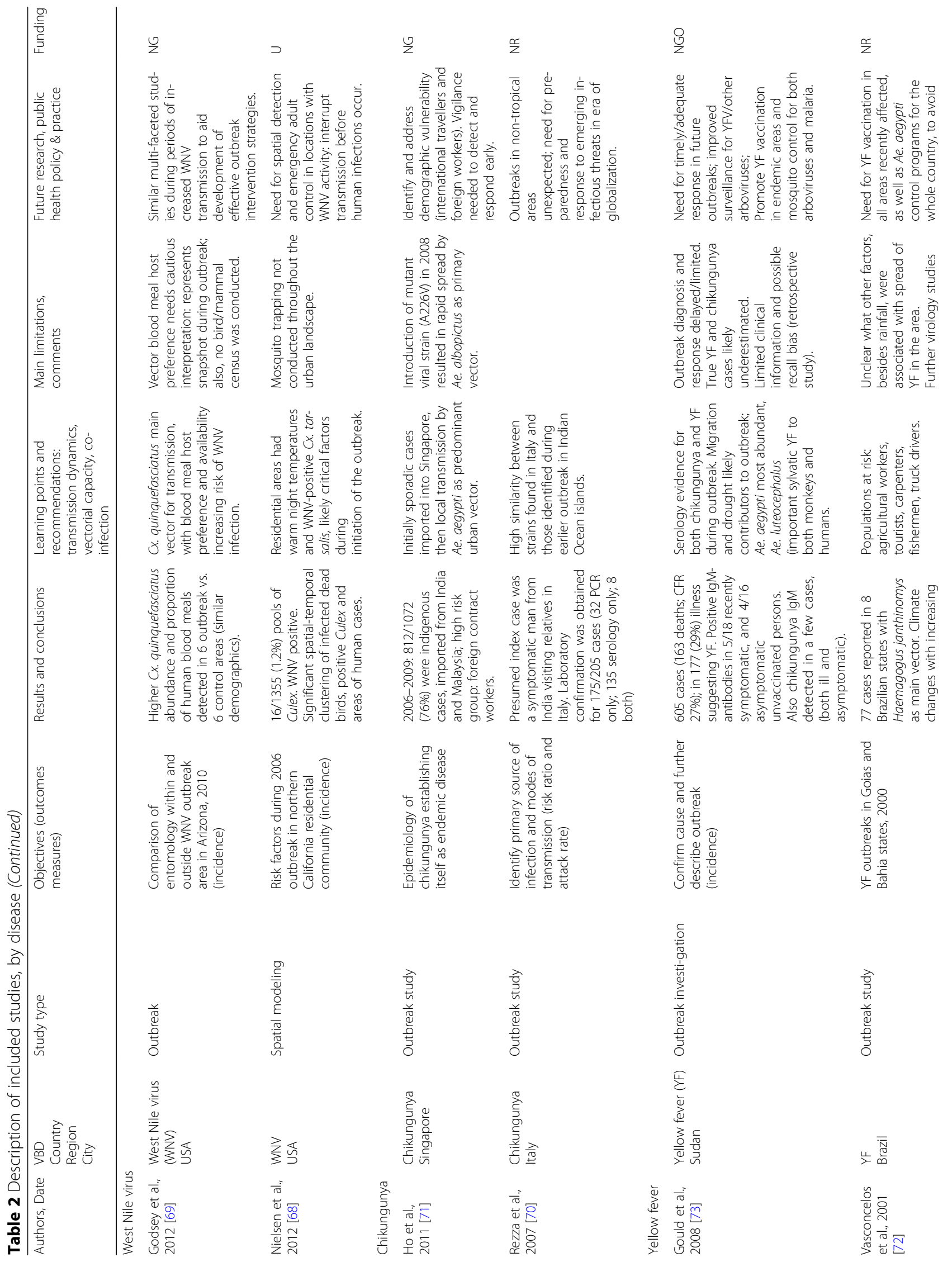




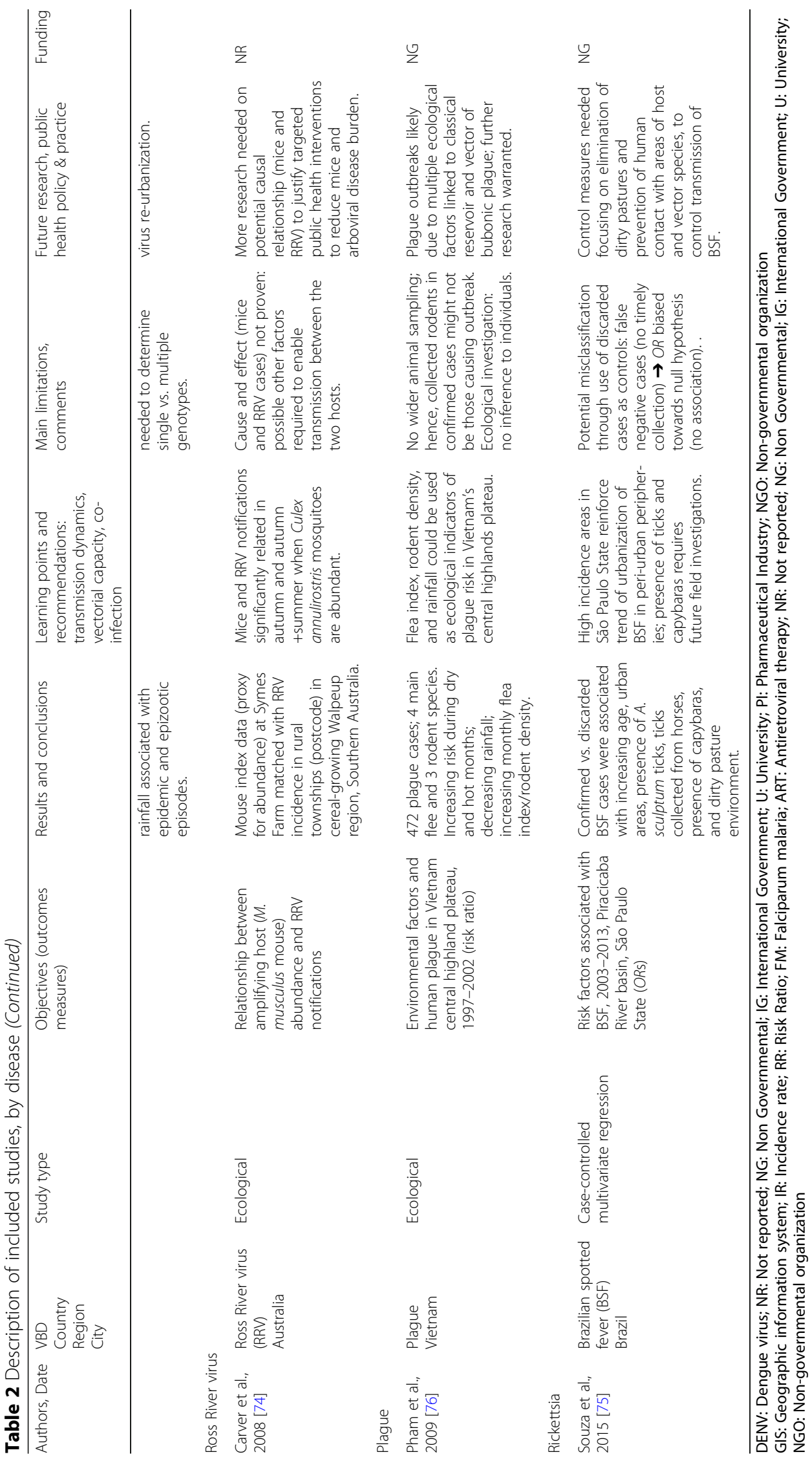




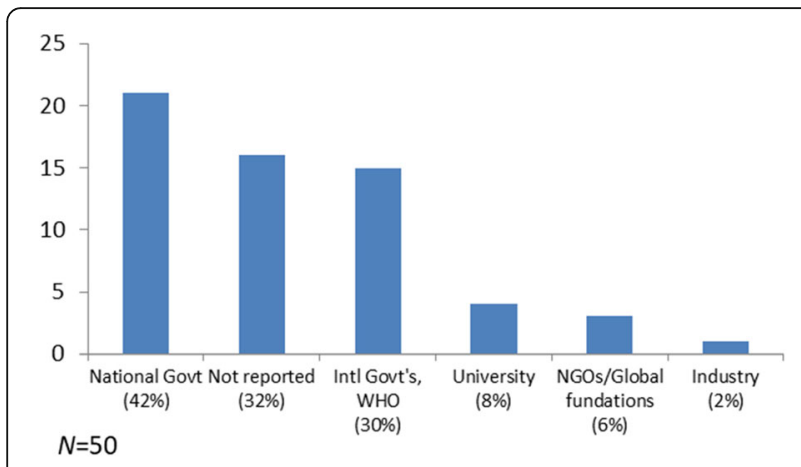

Fig. 3 Studies specified according to funding sources, some studies have more than one study source. Funding: not reported, $n=16$; national government, $n=21$; university, $n=4$; international government/WHO, $n=15$; non-governmental organizations, $n=3$; pharmaceutical industry, $n=1$ (some studies had more than one funding source).

is another important factor in the spread of dengue infections in urban settings [27]. The spread of dengue by imported cases has been reported in some countries, such as Argentina during the 2009 outbreak [29], as well as China in the outbreaks in the outskirts of Cixi [30] and Dongguan cities [31] and near Guangzhou Baiyun International Airport (2006-2012) [24]. The reports from China highlighted the role of immigrants from Southeast Asia as the source of localized outbreaks in this region.

\section{Vectorial capacity and incidence of dengue infection or disease}

There was conflicting evidence around indicators of vector abundance and incidence of dengue infection/disease. Positive associations between high vector density and high dengue incidence were reported in different settings, such as San Juan, Puerto Rico [32], Cuba [33],
Argentina [29], Brazil [34, 35] and Bangladesh [36]. In contrast, other studies showed inverse relationships between entomologic indices and dengue incidence [26, 37-39]. It has been well established that water storage containers and discarded tires are important mosquito habitats in many countries, which was also reinforced by studies in Puerto Rico [32] and French Guiana [40].

\section{Weather and climate variability and vector proliferation}

Studies conducted in different regions evaluated the role of weather on the proliferation of Aedes aegypti, dengue incidence, and the seasonality of the disease [30, 32, 39, 41-43]. Some ecological studies observed a positive association of temperature and rainfall with variations in the Aedes mosquito population [32, 38, 39]. Some studies conducted in the Americas showed a positive correlation of rainfall and temperature with dengue incidence [32, 41], while others in Asia found negative or no associations between these meteorological variables and dengue incidence [30, 42, 43]. In an interdisciplinary study (2010-2011) conducted in São Paulo, Brazil, using geographic information systems, more dengue cases were clustered in areas of land surface temperature above $32{ }^{\circ} \mathrm{C}$ than in areas characterized as low socioeconomic, high population density areas, or slum-like areas [39]. That study's findings were interpreted as suggesting that the land surface temperature of the inner city was a better predictor for dengue incidence than were other factors such as population density or socioeconomic indicators. Therefore, the influence of higher temperatures in small urban areas in São Paulo, known as urban heat islands, was correlated with high-risk areas of dengue transmission during this period (2010-2011) [39].

Table 3 Type of study methods, by disease group

\begin{tabular}{|c|c|c|c|c|c|c|c|c|}
\hline & Dengue $n=20$ & $\%$ & Malaria $n=15$ & $\%$ & Other $n=15$ & $\%$ & All $n=50$ & Total \% \\
\hline Outbreak & 2 & $10 \%$ & 0 & $0 \%$ & 7 & $47 \%$ & 9 & $18 \%$ \\
\hline Case-control (cluster) & 2 & $10 \%$ & 0 & $0 \%$ & 3 & $20 \%$ & 5 & $10 \%$ \\
\hline Cross-sectional & 2 & $10 \%$ & 4 & $27 \%$ & 1 & $7 \%$ & 7 & $14 \%$ \\
\hline Cohort (longitudinal) & 3 & $15 \%$ & 6 & $40 \%$ & 0 & $0 \%$ & 9 & $18 \%$ \\
\hline Analytical - multivariate & 6 & $30 \%$ & 5 & $33 \%$ & 5 & $33 \%$ & 16 & $32 \%$ \\
\hline Ecological (population study) & 4 & $20 \%$ & 0 & $0 \%$ & 5 & $33 \%$ & 9 & $18 \%$ \\
\hline Spatial modelling & 6 & $30 \%$ & 3 & $20 \%$ & 2 & $13 \%$ & 11 & $22 \%$ \\
\hline Time series regression, dynamic modelling & 3 & $15 \%$ & 2 & $13 \%$ & 0 & $0 \%$ & 5 & $10 \%$ \\
\hline Secondary data only & 5 & $25 \%$ & 4 & $27 \%$ & 1 & $7 \%$ & 10 & $20 \%$ \\
\hline Prevalence - Incidence & 15 & $75 \%$ & 13 & $87 \%$ & 13 & $87 \%$ & 41 & $82 \%$ \\
\hline Odds Ratio & 2 & $10 \%$ & 1 & $7 \%$ & 3 & $20 \%$ & 6 & $12 \%$ \\
\hline Risk Ratio or Similar & 3 & $15 \%$ & 2 & $13 \%$ & 3 & $20 \%$ & 8 & $16 \%$ \\
\hline
\end{tabular}

Methods applied in $n=50$ quantitative descriptive studies in numbers and \%, for dengue, malaria and other pathogens (some studies employ more than one different study method) 


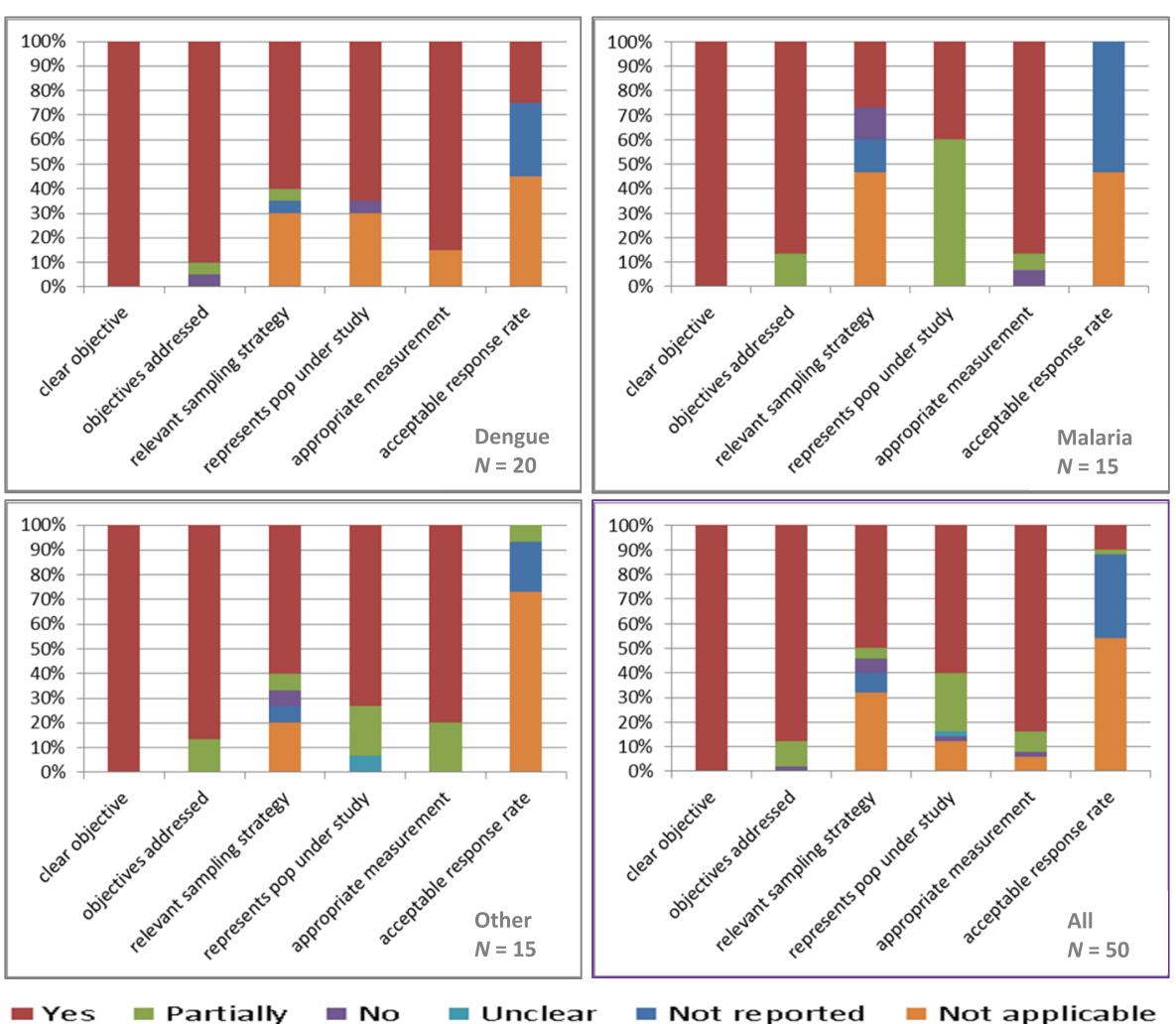

Fig. 4 Quality of studies according to modified MMAT tool in numbers (\%), for dengue, malaria and other pathogens

\section{Other social and environmental factors influencing or associated with the complexity of urban settings}

Other social and environmental factors associated with disease incidence and vector abundance include living and working conditions, human behaviour, urban infrastructure, and water and sanitation, which includes water storage conditions and housing quality [30, 32, 37, 40]. In Sudan, a study conducted in the neighbourhoods of the city of Port Sudan (2008-2009) [44], observed that dengue incidence was heterogeneously distributed and higher entomological density indices were found in lower- and middle-class neighbourhoods. In that setting, climate variability, maritime traffic, and socioeconomic conditions were suggested as being the main drivers of dengue outbreaks in the past decade, although further research will be required to study the impact of long-term climate change on dengue emergence in that region [44]. In Rio de Janeiro, Brazil, spatial analysis showed a positive association between social inequalities (Gini indices) and the container (Breteau) index for Aedes albopictus [41]. A serosurvey conducted in the US-Mexican border area found an abundance of vectors in US cities, but higher dengue incidence in neighbouring cities in Mexico. This lead the authors to conclude that population living conditions (low air conditioning rates, small living spaces, high numbers of occupants) were the main determinants of dengue transmission in that region, indicated by seroprevalence in each population [37].

\section{Malaria transmission dynamics and vectorial capacity studies}

The malaria research retrieved was mostly conducted in the African region, where yearly estimates indicate to be the highest burden of malaria cases (191 million cases in WHO African Region vs. 21 million in other parts of the world) and deaths; and the highest proportion of $\mathrm{Pl}$. falciparum (vs. other species) worldwide in 2016 [5]. At the same time there is the lowest level of health expenditure in this compared to other regions [45], further aggravating the impact of the disease on populations and economies.

\section{Incidence of malaria cases or infection}

There has been controversy about a potential expansion of malaria from rural areas into cities. Research evidence suggests increased malaria risk to urban dwellers, and transmission in urban and periurban setting [46]. In the studies selected in our review, increasing transmission risk was described as part of climatic changes affecting urban areas in the highlands of Ethiopia, and India, respectively [7, 47]. A study using small-scale temporal-spatial scanning identified "hotspots" of high Anopheles density and 
parasite carriage in two villages in Mali. However, transmission was also found to be high outside these hotspots, casting doubt on the effect of targeted control interventions in hotspots [48]. A transmission hotspot detected within $350 \mathrm{~m}$ of a large Anopheles breeding site during the 2003 outbreak in Ethiopia highlighted the potential of targeted vector control measures to reduce cases [49].

With regards to the occurrence of co-infections, Müller et al. [50] found a protective effect in children infected by multiple, genetically different $P l$. falciparum malaria parasite co-infections. Further, there was a protective effect against episodes of febrile illness during a three-month subsequent (passive) follow-up. The group found an 0.84 (95\% CI: 0.71-0.99) hazard associated with each additional Pl. falciparum genotype detected at baseline and called for more research into this phenomenon, in particular the effects on the host in chronic infections [50]. Another group studied malaria and helminth dual infections among pregnant women with HIV infections on treatment for $>1$ year. The study design was merely descriptive, showing co-infection rates to be higher in women living in urban areas than among those in rural areas [51]. The authors hypothesized regarding potential aggravating effects of co-infection on anemia, which is a consequence of each of these three types of infection (malaria, helminths, HIV).

\section{Mobility of human populations as a source of outbreaks and/or disease persistence}

Zhao et al. [52] found most malaria cases in Ningbo City, China, to be caused by $P l$. vivax imported from domestic endemic areas, leading to local transmission through Anopheles sinensis. The authors suggested that more research was needed on the role of floating populations in local malaria transmission [52]. Migration and travel were also identified as important risk factors for malaria re-introduction in Singapore, evidenced by an analysis of 25 -year reporting data. The authors advocated for screening, education, and good case management. Finally, they suggested that also simian Plasmodium knowlesi malaria would need to be considered as a possible source of fever in their study population [53].

\section{Vectorial capacity and the incidence of malaria infection or disease}

Several studies demonstrated changes in vector composition according to geography and season to explain variations in transmission [47, 52, 54, 55]. There was diversity among studies on the correlation between entomological parameters and human malaria. The EIR as indicator for transmission was found to correlate with clinical prevalence and incidence data in Nigeria [56], similar to Anopheles density and malaria cases in
Ningbo, China [52]. An important factor for malaria transmission in forested villages in Venezuela was the presence of mosquito species displaying predominantly exophagic (outdoor) biting behaviour [57].

In contrast, no correlation was found between EIR and percentage of malaria among reported fever cases in India [54], nor between Anopheles density and human case rates in French Guiana, and the authors argue the mosquito traps might have been located in non-transmission areas [58].

\section{Weather and climate variability and vector proliferation}

Increased transmission during the rainy season has been observed in Africa and Asia [7, 54, 59]. More specifically, increasing temperature and rainfall were followed by higher vector prevalence transmission models based on four different areas of Burkina Faso, with peak vector prevalence occurring 2 weeks after peak rainfall [60]. In northwest China, monthly An. sinensis vector density (relevant for $\mathrm{Pl}$. vivax malaria transmission) was strongly correlated not only with temperature $(R=0.958$, $P<0.001)$, but also with humidity and rainfall $(R=0.746$, $P=0.005$; and $R=0.725, P=0.008$, respectively) [52]. Furthermore, increases in average maximum and minimum temperatures (at 1 month lag) and rainfall (10-week lag) in Ethiopia had malaria incidence risk ratios of 1.4 (for maximum temperature), 1.3 (for minimum temperature), and 1.0 (for rainfall) [49]. Zhang et al. (2012) showed malaria epidemiology in China to have strong spatial associations with average temperature. They proposed optimizing case management rather than vector control for low-transmission areas [55].

Other environmental factors, geography, and complexity of urban setting influencing malaria infection or disease

Peterson et al. (2009) identified not only proximity to a large Anopheles breeding site as a source of increased transmission, but also poor housing as a further important risk factor (malaria incidence risk ratio $=2.0$ ) in Adama, Ethiopia [49]. Similar observations were made in semi-arid neighbouring Sudan, where transmission was higher in rapidly expanding peri-urban low-income areas than in suburban higher-income areas of Khartoum [59].

Certain ecological areas show higher malaria transmission than others. In Nigeria, transmission rates (MBR and EIR) were higher near mangrove coastal water than in areas of fresh or brackish water [56]. In Ethiopia, proximity to vegetation and to agricultural sites showed higher vector density and more cases $[49,54,59]$.

Further, changes to ecology and climate were considered to be causing increasing malaria transmission in urbanized highland areas of Africa and Asia [7, 47]. Capable Anopheles vectors and short-term malaria 
transmission were observed during the rainy season (due to short-term extra breeding sites) in Ethiopia, where low population immunity between seasons causes epidemics [7]. Comparison of three villages at different altitudes in India showed both reduced Anopheles abundance and transmission windows for human cases with increasing altitude [47]. Geographic expansion of mosquito vectors has been described as one of the possible effects of climate change [61].

Summarizing key insights from respective groups of authors, there was an expression of need to address the increased risk of transmission in vulnerable highland areas $[7,47]$ and in spaces where specific risk factors are present, including proximity to breeding sites, poor housing [49], low income [49], and floating populations $[52,53]$. They recommended better ways to monitor and address risk factors via spatial studies and forecast models that include entomological parameters and meteorological factors. Further, the significance of asymptomatic infections was expressed in reports on parasitaemia and floating populations, identifying the need to detect and treat such cases to prevent transmission $[52,53,59]$. Finally, the complexity and potential impact of co-infections on the host have been recognised $[50,51]$.

\section{Other diseases}

Four studies focused on leishmaniasis: two on cutaneous leishmaniasis (in Argentina and Brazil) $[62,63]$ and two on visceral leishmaniasis (in Brazil and Nepal) [64, 65]. Agricultural male workers were identified as a risk group; further associated factors included peri-urban living environment, low socioeconomic status, poor housing, and domestic dogs. All reports demonstrated the need for improved surveillance and control measures, to reduce infection risk both in urban and peri-urban areas, with specific focus on dog populations.

Chagas disease was detected in young individuals in Mexico (1\% of people aged < 18 years) [66] and Bolivia ( $>20 \%$ of school children aged 5-13 years). Poor housing and high infection rates among transmitting vectors were identified as important risk factors; the authors suggested prioritizing detection and control programs in these urban areas [67].

West Nile virus (WNV) is a VBD in which bird populations such as corvids serve both as important reservoir and amplifiers, whereas migratory birds are involved in global transmission [68]. Researchers in the United States (US) correlated mosquito and local bird population WNV status with human incidence. They identified Culex mosquitoes as important vectors in the Arizona outbreak where their abundance and (bird) host preference increased the risk of human transmission, and compared to control sites in the metropolitan area of
Phoenix (US) [69]. A spatial study identified significant clustering of infected dead birds and positive Culex mosquitoes near human cases occurring in residential areas of California [68]; early detection was proposed as a key to reducing the risk of outbreaks.

\section{Role of tourism, migration and occupational exposure on transmission of infection}

Two studies reviewed chikungunya occurrence, one in Italy following virus introduction by a symptomatic individual visiting from India [70] and the other in Singapore, where recent virus mutation allowed the infection to be effectively transmitted by urban Aedes albopictus mosquitoes [71]. Both research groups highlighted the role of migrants in the spread of disease and the need for effective disease surveillance to prevent outbreaks.

In Brazil, researchers identified a yellow fever transmission link to tourism and occupational exposure (agricultural workers, carpenters, fishermen, truck drivers) and to Haemagogus janthinomys as the main mosquito vector [72]. In Sudan, drought, migration, and the lack of diagnostic capabilities or adequate response contributed to a yellow fever outbreak where there was concurrent transmission of chikungunya [73].

\section{Influence of disease ecology on transmission}

A field survey found seasonal abundance of amplifying mouse populations to increase Ross River virus (RRV) transmission in Australia, combined with the presence of the Culex annulirostris vector. The authors proposed more specific research on the causal relationship between mice and RRV, along with possible interventions to control the disease [74].

Bacterial diseases studied included tick-transmitted Brazilian spotted fever (BSF) in Brazil [75] and human bubonic plague in the Vietnam Central Highland plateau [76], for which multiple ecological factors were identified, and the authors proposed using rodent density and rainfall as ecological risk indicators.

\section{Discussion}

Dengue and malaria studies constituted the largest groups of published research in our review-dengue predominantly in Asia and the Americas, and malaria in Africa. Dengue has the highest burden and vectors capable of transmitting in urban and peri-urban areas of these regions. The urbanization of the population in Africa has also reflected in malaria transmission that can be currently considered an urban problem [77]. Despite being different pathogens (protozoa vs. virus), both VBDs, despite spread by different mosquito species can be framed with regards to the importance ofurban heat islands and eco-zones, human habitat (proximity to 
breeding sites), host behaviour and mobility, the role of asymptomatic infections, and association with increased temperature and rainfall (albeit more evidence is required on the associations between climate variability and dengue incidence to explain the discrepancies in recent studies) promoting vector abundance and associated disease incidence. Since the beginning of $1900 \mathrm{mal}-$ aria research employed the theory of Ross-MacDonald for the dynamics and control of mosquito-transmitted pathogens. This transmission model has now been adopted for dengue research, which has become more intensified in recent years as the disease is becoming a global problem [19].

Dengue transmission and vectorial capacity have been studied mainly using the conventional framework of interaction between human and mosquito populations. A bulletin of the World Health Organization highlighted the importance of increasing residents' knowledge regarding dengue transmission, which was associated with a measurably lower mosquito reproduction in the respective areas [78]. This was presented as an example of how broader public health efforts (beyond larvicide and focal spraying) can contribute to effective vector control [78]. There is a lack of translational research and a need to combine multiple knowledge areas involving urban planners, travel and border agencies, transport authorities, environmentalists [79]. Such integration would be an useful approach to better understand and respond to the complexity of dengue dynamics in urban settings. Only a few studies addressed this using information on previous dengue serotype immune status to understand disease spread and persistence.

None of the selected studies assessed the co-circulation of VBDs transmitted by the same vector, such as dengue, chikungunya and Zika, which coexist in many regions across the globe [11]. A syndromic approach focusing on patients' main symptoms, such as fever and rash (equally common symptoms for dengue, chikungunya, Mayaro, Zika, etc.), rather than only on isolated pathogens, might help to adapt VBD research more effectively to the clinical-epidemiological reality. Combining such an approach with broad diagnostics (e.g. testing for a panel of common vector-transmitted parasites, viruses, and bacteria) would allow easy detection of and response to co-circulating vectors, including newly emerging pathogens. This is particularly true for a coordinated international response to new pathogen introductions or epidemics, such as Zika in the America. Harmonization of syndrome-based protocols would increase the effectiveness of such efforts.

Similarly, malaria has been studied largely in conventional frameworks. In some studies, quality was very basic: questionable sampling techniques (convenience sampling), no indication of the proportion of non-responders, offering only passive rather than active follow-up, location of mosquito traps not matching with areas of human transmission-all of which created risks of bias. Also, most studies were descriptive (i.e., using measures of occurrence) rather than providing robust figures of transmission risk (measures of effect). Further, a multidisciplinary approach, as suggested above, could have provided essential insights into the role of asymptomatic infections, especially among floating populations.

Discussing other infections than dengue and malaria, we detected recommendations on specific surveillance and control measures that were included in most studies. For example, the need for entomological surveillance and control in detecting risk areas for Leishmaniasis [62, 63, 65], Chagas' disease [66, 67], and arboviruses (West Nile Virus [68, 69], Chikungunya [71]), and plague [76]. Also, the need of targeted surveillance and interventions focusing on important animal reservoirs for Leishmaniasis (dog population) [63, 64], West Nile Virus (clustering of dead birds) [68], Ross River Virus (abundance of house mice), and plague /BSF (rodents) $[75,76]$. The importance of increasing such measures specifically in urban and periurban areas was highlighted in relation to Leishmaniasis [62, 64, 65], Chagas'disease [67], West Nile virus [68] and BSF [75]. In addition, enhancing vigilance around migration and travel are needed to reduce risk for spreading of Chikungunya $[70,71]$ and Yellow Fever [72, 73]. For the latter, the importance of vaccination programs was mentioned $[72,73]$. Considering that two thirds of the studies were funded by government sources (national or international) the an integrated approach including human and animal health, and entomology should be reinforced. The Joint external evaluation tool by the World Health Organisation as part of Global Health Security is an example for multi-sector and multi-disciplinary effort. This agenda considers multiple hazards, including detection and control of priority epidemic diseases, border surveillance, using an integrated 'One Health' approach including human, animal and environmental health [80].

This scoping review has some limitations.

Performing a detailed data extraction on all 205 papers was considered as unfeasible by the consortium. Therefore, an additional step to include only studies that covered at least two of the key concepts (i.e. "transmission dynamics and vectorial capacity" and, "transmission dynamics and co-infection") limited the number of papers. An additional benefit of this approach was a more comprehensive picture that combined at least two components of infectious diseases in urban areas. At the same time, we acknowledge limitations arising from this 
final step, which may have excluded important papers reporting only one key concept. That way, classical modelling studies, (particularly those dealing solely with mathematical models (for prediction of outbreaks, spread of infection, and/or long term sustainability of transmission) may have been missed [17, 18, 81].

Further limitations relate to quality and comparability of selected work. Only a few studies went beyond description, as shown by MMAT evaluation of the quality of studies. Clear objectives were set out in all studies and were addressed to a fairly large extent. However, concerns about study quality arose regarding $10-20 \%$ of studies, which did not report the relevant sampling strategy. Compared to the studies on other pathogens, the malaria studies were less representative of true population (therefore producing less generalizable results), due to their designs, which were mostly smaller-volume cross-sectional and cohort studies.

Also, there was no attempt to stratify by population size. Stratification would have allowed to identify challenges specific to highly populated urban areas as opposed to smaller urban areas like villages. Dengue is a VBD amplified by humans (rather than other non-human hosts) which contributes to large scale transmission in cities. In contrast, transmission dynamics for a number of other pathogens included (e.g. Leishmaniasis, West Nile Virus, Yellow Fever, Ross River virus and plague) rely on non-human host species, such non-human primates, dogs, rodents or birds. Presence of those species will depend on different types of urban and peri-urban environments and other factors. The same applies for the type of insect vectors implicated. From this perspective, further work classifying between different urban environments will be useful.

The difference in methods used by studies is one factor limiting the comparability, particularly on study that combined weather and entomological data to predict VBD incidence [24, 31, 42, 60]. Differences also arose in the researchers' selections of the most appropriate ways to control for factors such as seasonality and non-linearity of weather dependence, as pointed out in a technical paper on temporal modeling research [82]. Of note is that, to our knowledge, there are currently no international standards to advise on the most appropriate modeling approach for real-time prediction to inform public health practice.

Finally, another limiting factor was that only two studies reported on co-infections, and both of those addressed malaria. This is concerning in view of how little is known about this phenomenon, the immunological mechanisms involved, and what it means for clinical outcomes; even less is known about transmission dynamics.
Box 1 The main implications for future research and public health policy and/or practice

Knowledge gaps and priority needs for future research

1. Assess the magnitude of asymptomatic dengue infection at population level (surveillance of symptomatic dengue cases is insufficient to evaluate the persistence of infection).

2. Improve indoor and outdoor vector density parameters for more accurate modeling of transmission.

3. More studies are needed on climate and other environmental (e.g. land surface temperature) changes and their effect on vector proliferation and dengue transmission.

4. The impacts of human mobility within and between cities and countries should be prioritized in future research.

5. Enhance research and seek scientific consensus on the benefit of simple, ready-to use forecasting tools to predict human VBD risk (using entomological, meteorological, and other parameters).

6. Promote research on co-infections with different pathogens, on immunology mechanisms and their effect on clinical outcomes and onward transmission, and on means of effective diagnosis and treatment

Implications for public health policy and/or practice

1. In dengue-endemic areas, monitoring areas of low transmission may be necessary to prevent spread of infection.

2. Surveillance and control strategies focused on index cases should be timely to avoid time lag between outbreak onset and response.

3. Asymptomatic individuals contribute to persistence of dengue and malaria transmission, reinforcing the need for population screening (e.g. biological marker laboratory testing blood banks, sentinel sites), in low and high seasonality.

4. Need to assess multiple data sources regarding symptomatic and asymptomatic cases.

5. Surveillance and control strategies focused on index cases should be timely to stop transmission.

6. Greater efforts must be made to translate knowledge about VBD transmission into practice.

7. Employ scientifically agreed-upon ready-to use forecast models to predict human VBD risk based on entomological and meteorological parameters.

8. Increased rainfall and humidity, especially during the rainy season, affects VBD transmission; authorities need to collaborate to heighten vigilance and control measures.

9. Poor housing, low-income neighbourhoods are high-risk areas for VBD transmission; they should be focus of affordable and sustainable vector control measures in homes, workplaces and schools, to lower transmission over the long term.

10. Certain occupational groups have higher exposure to VBDs; labour and agricultural authorities must invest in efforts to increase awareness and safety in relation to specific disease risks.

11. Transport authorities and border agencies need to screen floating populations at risk of infection.

12. Using a syndromic approach instead of the classic single-disease surveillance would allow timely response to the introduction of new pathogens or early outbreak detection.

13. Harmonization of protocols are needed to facilitate a coordinated international effort to control disease threats of national/international importance. National government and academic institutions to promote an integrated multi-disciplinary approach (human and animal health, vector control), focusing on detection and control of priority epidemic diseases, border surveillance. 


\section{Conclusions}

The present review identified significant knowledge gaps in several areas, ranging from the role of asymptomatic individuals to the effects of co-infection and various host characteristics, climate, and other environmental and socioeconomic factors on VBD transmission in urban areas. There is much more to know about transmission risk in the homes and workplaces of increasingly dynamic and mobile populations.

The lack of studies on co-infection is hampering the monitoring of infections transmitted by the same vector. A broad, syndromic approach including pathogen panels would allow more flexibility in detecting new and co-circulating pathogens and in applying more effective control. It would be useful to combine this with harmonized protocols and to define sentinel areas in order to enable a well-coordinated international response where needed. Due to the complexity of VBD transmission, funding for translational research is especially recommended.

\section{Additional files}

Additional file 1: Multilingual abstracts in the six official working languages of the United Nations. (PDF $390 \mathrm{~kb}$ )

Additional file 2: Literature search: Associated keywords, MESH and search terms. (DOCX $25 \mathrm{~kb}$ )

Additional file 3: Final reference selection by country. (DOCX 15 kb)

\section{Abbreviations}

ART: Antiretroviral therapy; BSF: Brazilian spotted fever; CAR: Conditional Autoregressive; CFR: Case fatality rate; CL: Cutaneous Leishmaniasis; EIR: entomological inoculation rate; FM: Falciparum malaria; IG: International Government; IR: Incidence rate; LST: Land Surface Temperature; MBR: Man biting rate; MMAT: Mixed Methods Appraisal Tool; n.s.: Not significant (statistically); NG: Non Governmental; NGO: Non-governmental organization; NR: Not reported; OR: Odds ratio; PCR: Polymerase Chain Reaction; Pl: Pharmaceutical Industry; PR: Prevalence rate; RF: Risk factors; RR: Risk Ratio; RRV: Ross River virus; TDR: Tropical Diseases Research and Training; TIDieR: Template for Intervention Description and Replication; TL: Tegumentary Leishmaniasis; U: University; UHI: Urban Heat Island; VBDs: Vector-borne diseases; VL: Visceral Leishmaniasis; WHO: World Health Organization; WNV: West Nile virus; YF: Yellow Fever; YFV: Yellow Fever Virus

\section{Acknowledgements}

We would like to thank Sylvie Fontaine, public health research librarian at the University of Montreal, for her careful review of the search strategy and Mariam Otmani del Barrio, from the Unit on Vectors, Environment and Society at $\mathrm{WHO}$, for her comments on our final manuscript. This study was conducted as part of the VERDAS consortium project, funded by the Special Program for Tropical Diseases Research and Training (TDR) of the World Health Organization. Partial support from the National Advisory Board of Scientific and Technological Development (Conselho Nacional de Desenvolvimento Cientifico e Tecnologico [CNPq]; scholarship to CMTM 306708/2014-0 and to CB 304174/2014-9).

\section{Funding}

VERDAS Consortium.

Availability of data and materials Not applicable.

\section{Authors' contributions}

ME, FC, NTSF, CB, CMTM participated in the design, study selection, data extraction and analysis, and write-up of this study. SD and VR participated in the design of this study and revised the manuscript. GVAF participated in the revision of the manuscript. All authors approved the final version.

Ethics approval and consent to participate

The study protocol was approved by the University of Montreal Human Research Ethics Committee.

\section{Consent for publication}

Not applicable.

\section{Competing interests}

The authors declare that they have no competing interests.

\section{Author details}

'Public Health England Sierra Leone Country Office, Freetown, Sierra Leone. ${ }^{2}$ Aggeu Magalhaes Institute (IAM) / Oswaldo Cruz Foundation (Fiocruz), Avenida Professor Moraes Rego, s/n. Cidade Universitaria. CEP 50, Recife, Pernambuco 740-465, Brazil. ${ }^{3}$ Universidade de Pernambuco (UPE), Recife, Pernambuco, Brazil. ${ }^{4}$ Liverpool School Of Tropical Medicine (LSTM), London, UK. ${ }^{5}$ Secretariat of Health Surveillance, Ministry of Health, Brasilia, Brazil. ${ }^{6}$ University of Montreal School of Public Health (ESPUM), Montreal, Quebec, Canada. ${ }^{7} \mathrm{IRD}$ (French Institute For Research on Sustainable Development), CEPED (IRD-Université Paris Descartes), Universités Paris Sorbonne Cités, ERL INSERM SAGESUD, Paris, France.

Received: 8 February 2018 Accepted: 2 August 2018

Published online: 03 September 2018

\section{References}

1. World Health Organization. Vector-borne diseases [Internet]. 2016 [cited 2017 Aug 17]. Available from: http://www.who.int/en/news-room/factsheets/detail/vector-borne-diseases.

2. Anderson R, May R. Infectious diseases of humans: Oxford Science Publications; 1991

3. Kramer LD. Complexity of virus - vector interactions. Curr Opin Virol. 2016; 21:81-6.

4. Heesterbeek $H$, Anderson R, Andreasen V, Bansal S, De D, Dye C, et al. Modeling infectious disease dynamics in the complex landscape of global health. Science (80- ). 2015;347:aaa4339.

5. World Health Organization. World Malaria Report. Geneva. 2016:2016.

6. Wilson ML, Krogstad DJ, Arinaitwe E, Arevalo-Herrera M, Chery L, Ferreira $\mathrm{MU}$, et al. Urban malaria: understanding its epidemiology, ecology, and transmission across seven diverse ICEMR network sites [Internet]. 3, Suppl. ed. Spec. Issue Int. Centers Excell. Malar. Res. background, progress, ongoing Act. USA; 2015. p. 110-23. Available from: https://www.ajtmh.org/content/ journals/10.4269/ajtmh.14-0834

7. Woyessa A, Gebre-micheal T, Ali A. An indigenous malaria transmission in the outskirts of Addis Ababa, Akaki town and its environs. EthiopJHealth Dev. 2004;18:2-8.

8. Brady OJ, Smith DL, Scott TW, Hay SI. Dengue disease outbreak definitions are implicitly variable. Epidemics. Elsevier B.V. 2015;11:92-102.

9. Halstead SB. Dengue Virus-Mosquito Interactions. Annu Rev Entomol. [Internet]. 2008;53:273-91.

10. Fauci AS, Morens DM. Zika virus in the Americas-yet another arbovirus threat. N Engl J Med. 2016;374:601-4.

11. Musso D, Cao-Lormeau VM, Gubler DJ. Zika virus : following the path of dengue and chikungunya ? Lancet Elsevier Ltd. 2015;386:243-4.

12. World Health Organization. Neglected tropical diseases - Fact sheets relating to NTD. 2017.

13. United Nations. World Urbanization Prospects: The 2014 Revision, Highlights (ST/ESA/SER.A/352). New York, United. 2014

14. Alirol E, Getaz L, Stoll B, Chappuis F, Loutan L. Urbanisation and infectious diseases in a globalised world. Lancet Infect Dis Elsevier Ltd. 2010;11:131-41.

15. Hassell JM, Begon M, Ward MJ, Fèvre EM. Urbanization and Disease Emergence : Dynamics at the Wildlife - Livestock - Human Interface. Trends Ecol Evol. The Author(s); 2017;32:55-67. 
16. Struchiner CJ, Rocklöv J, Wilder-smith A. Increasing dengue incidence in Singapore over the past 40 years : population growth. Climate and Mobility PLoS One. 2015:1-14.

17. Amaku M, Azevedo F, Burattini MN, Coelho GE, Coutinho FA, Greenhalgh D, Lopez LF, Motitsuki RS, Wilder-Smith A, Massad E. Magnitude and frequency variations of vector-borne infection outbreaks using the Ross-Macdonald model: explaining and predicting outbreaks of dengue fever. Epidemiol Infect. 2016;144(16):3435-50.

18. de Castro Medeiros LC, Castilho CAR, Braga C, de Souza WV, Regis L, Monteiro AMV. Modeling the dynamic transmission of dengue fever: investigating disease persistence. PLoS Negl Trop Dis. 2011;5:e942.

19. Perkins TA, Reiner RC, Rodriguez-Barraquer I, Smith DL, Scott TW, Cummings DAT. A review of transmission models of dengue: a quantitative and qualitative analysis of model features. Dengue and dengue hemorrhagic fever. 2nd ed. Wallingford: CABl; 2014. p. 99-114.

20. Reiner RC, Stoddard ST, Forshey BM, King AA, Ellis AM, Lloyd AL, et al. Timevarying, serotype-specific force of infection of dengue virus. Proc Natl Acad Sci U S A. 2014;

21. Arksey H, O'Malley L. Scoping studies: towards a methodological framework. Int J Soc Res Methodol. 2007;8:19-32.

22. Pace R, Pluye P, Bartlett G, Macaulay AC, Salsberg J, Jagosh J, et al. Testing the reliability and efficiency of the pilot mixed methods appraisal tool (MMAT) for systematic mixed studies review. Int J Nurs Stud. 2012:49:47-53.

23. Hoffmann TC, Glasziou PP, Boutron I, Milne R, Perera R, Moher D, et al. Better reporting of interventions: template for intervention description and replication (TIDieR) checklist and guide. BMJ. 2014;348

24. Sang $S$, Yin W, Bi $P$, Zhang $H$, Wang $C$, Liu $X$, et al. Predicting local dengue transmission in Guangzhou, China, through the influence of imported cases, mosquito density and climate variability. PLoS One. 2014/07/16. 2014;9:e102755.

25. Teixeira MDG, Barreto ML, Costa MDCN, Ferreira LDA, Vasconcelos PFC, Cairncross S, et al. Dynamics of dengue virus circulation: A silent epidemic in a complex urban area. Trop Med Int Heal. 9th ed. United Kingdom: Blackwell Publishing Ltd (9600 Garsington Road, Oxford OX4 2XG, United Kingdom); 2002;7:757-62.

26. Méndez F, Barreto M, Arias JF, Rengifo G, Muñoz J, Burbano ME, et al. Human and mosquito infections by dengue viruses during and after epidemics in a dengue-endemic region of Colombia. Am J Trop Med Hyg. 2006;74:678-83.

27. Martínez-Vega RA, Danis-Lozano R, Díaz-Quijano FA, Velasco-Hernández J, Santos-Luna R, Román-Pérez S, et al. Peridomestic infection as a determining factor of dengue transmission. PLoS Negl Trop Dis. 2015:9:1-18.

28. Anders KL, Nga LH, Thuy NT V, Ngoc TV, Tam CT, Tai LTH, et al. Households as Foci for Dengue Transmission in Highly Urban Vietnam [Internet]. 2nd ed. United States: Public Library of Science (E-mail: plos@plos.org); 2015. p. no pagination. Available from: http://journals.plos.org/plosntds/article?id=10. 1371/journal.pntd.0003528.

29. Estallo EL, Carbajo AE, Grech MG, Frias-Cespedes M, Lopez L, Lanfri MA, et al. Spatio-temporal dynamics of dengue 2009 outbreak in Cordoba City, Argentina. Acta Trop. 2014/05/06. 2014;136:129-36.

30. Yang T, Lu L, Fu G, Zhong S, Ding G, Xu R, et al. Epidemiology and vector efficiency during a dengue fever outbreak in Cixi, Zhejiang Province, China [Internet]. 1st ed. USA; 2009. p. 148-154. Available from: http://www3. interscience.wiley.com/cgi-bin/fulltext/122509729/HTMLSTART

31. Peng HJ, Lai HB, Zhang QL, Xu BY, Zhang H, Liu WH, et al. A local outbreak of dengue caused by an imported case in Dongguan China. BMC Public Health. 2012/01/27. 2012;12:83

32. Barrera R, Amador M, MacKay AJ. Population dynamics of Aedes aegypti and dengue as influenced by weather and human behavior in San Juan, Puerto Rico. PLoS Negl Trop Dis. 2011/12/30. 2011;5:e1378.

33. Sanchez L, Vanlerberghe V, Alfonso L, Marquetti MDC, Guzman MG, Bisset J, et al. Aedes aegypti larval indices and risk for dengue epidemics [Internet]. 5th ed. United States: Centers for Disease Control and Prevention (CDC) (1600 Clifton Road, Mailstop C-12, Atlanta GA 30333, United States); 2006. p. 800-6. Available from: https://www.ncbi.n/m.nih.gov/pmc/articles/ PMC3374431/

34. Correa PR, Franca E, Bogutchi TF. [Aedes aegypti infestation and occurrence of dengue in the city of Belo Horizonte, Brazil]. Rev Saude Publica. 2005/01/ 18. 2005;39:33-40.

35. Dibo MR, Chierotti AP, Ferrari MS, Mendonca AL, Chiaravalloti Neto F. Study of the relationship between Aedes (Stegomyia) aegypti egg and adult densities, dengue fever and climate in Mirassol, state of Sao Paulo, Brazil. Mem Inst Oswaldo Cruz. 2008/10/25. 2008;103:554-60.

36. Ali M, Wagatsuma $Y$, Emch M, Breiman RF. Use of a geographic information system for defining spatial risk for dengue transmission in Bangladesh: Role for Aedes albopictus in an urban outbreak [Internet]. 6th ed. United States: American Society of Tropical Medicine and Hygiene (60 Revere Drive, Suite 500, Northbrook IL 60062, United States); 2003. p. 634-40. Available from: https://www.researchgate.net/profile/Mohammad_Ali55/publication/ 8904823_Use_of_a_geographic_information_system_for_defining_spatial_ risk_for_dengue_transmission_in_Bangladesh_Role_for_Aedes_albopictus_ in_an_urban_outbreak/links/Of31752f1dd631f6fe000000.pdf.

37. Reiter $P$, Lathrop S, Bunning $M$, Biggerstaff $B$, Singer $D$, Tiwari $T$, et al. Texas lifestyle limits transmission of dengue virus [Internet]. 1st ed. United States: Centers for Disease Control and Prevention (CDC) (1600 Clifton Road, Mailstop C-12, Atlanta GA 30333, United States); 2003. p. 86-9. Available from: https://www.ncbi.nlm.nih.gov/pmc/articles/PMC2873752/.

38. Teixeira MG, Costa MCN, Natividade MS, Carmo EH, Carneiro DDT. New epidemiologic profile of visceral leishmaniasis in an urban endemic/ epidemic area of Brazil [Internet]. Blackwell Publishing Ltd; 2015. p. 220.

39. Araujo R V, Albertini MR, Costa-da-Silva AL, Suesdek L, Franceschi NCS, Bastos NM, et al. Sao Paulo urban heat islands have a higher incidence of dengue than other urban areas [Internet]. 2nd ed. Brazil; 2015. p. 146-155. Available from: http://www.sciencedirect.com/science/article/pii/ S1413867014002074

40. Fouque F, Garinci R, Gaborit P. Epidemiological and entomological surveillance of the co-circulation of DEN-1, DEN-2 and DEN-4 viruses in French Guiana. 1st ed. UK; 2004. p. 41-46.

41. Teixeira TR, Cruz OG. Spatial modeling of dengue and socio-environmental indicators in the city of Rio de Janeiro, Brazil. Cad Saude Publica. 2011/04/ 27. 2011:27:591-602

42. Chang FS, Tseng YT, Hsu PS, Chen CD, Lian le B, Chao DY. Re-assess Vector Indices Threshold as an Early Warning Tool for Predicting Dengue Epidemic in a Dengue Non-endemic Country. PLoS Negl Trop Dis. 2015/09/15. 2015;9: e0004043.

43. Wu PC, Guo HR, Lung SC, Lin CY, Su HJ. Weather as an effective predictor for occurrence of dengue fever in Taiwan. Acta Trop. 2007/07/07. 2007;103: 50-7

44. Seidahmed OME, Hassan SA, Soghaier MA, Siam HAM, Ahmed FTA Elkarsany MM, et al. Spatial and Temporal Patterns of Dengue Transmission along a Red Sea Coastline: A Longitudinal Entomological and Serological Survey in Port Sudan City [Internet]. 9th ed. United States: Public Library of Science (185 Berry Street, Suite 1300, San Francisco CA 94107, United States); 2012. p. no pagination. Available from: http://journals.plos.org/ plosntds/article?id=10.1371/journal.pntd.0001821.

45. World Health Organization. WHO Global Health Expenditure Atlas [Internet]. 2014 [cited 2018 May 17]. Available from: http://www.who.int/nha/atlas.pdf

46. Keiser J, Utzinger J, Caldas de Castro M, Smith TA, Tanner M, Singer BH. Urbanization in sub-saharan Africa and implication for malaria control. Am J Trop Med Hyg. 2004/08/28. 2004;71:118-27.

47. Dhiman RC, Yadav YK, Shweta S, Poonam S. Altitude, temperature, and malaria vectors in Nainital and Udham Singh Nagar districts of Uttarakhand, India: an evidence-based study [Internet]. 3rd ed. India; 2013. p. 220-224. Available from: https://s3.amazonaws.com/academia.edu.documents/ 34068470/paper.pdf?AWSAccessKeyld=AKIAIWOWYYGZ2Y53UL3A\&Expires= $1533631438 \&$ Signature $=$

RqMJv\%2BivXXzRWHJdbAx\%2B8zOvoKw\%3D\&response-contentdisposition= inline\%3B\%20filename\%3DAltitude temperature and malaria_vectors.pdf

48. Sissoko MS, van den Hoogen LL, Samake Y, Tapily A, Diarra AZ, Coulibaly M, et al. Spatial Patterns of Plasmodium falciparum Clinical Incidence, Asymptomatic Parasite Carriage and Anopheles Density in Two Villages in Mali. Am J Trop Med Hyg. 2015/09/02. 2015;93:790-7.

49. Peterson I, Borrell LN, El-Sadr W, Teklehaimanot A. A temporal-spatial analysis of malaria transmission in Adama, Ethiopia. Am J Trop Med Hyg. 2009/12/10. 2009;81:944-9.

50. Müller DA, Charlwood JD, Felger I, Ferreira C, do Rosario V, Smith T. Prospective risk of morbidity in relation to multiplicity of infection with Plasmodium falciparum in Sao Tome. Acta Trop. 2001/03/07. 2001;78:155-62.

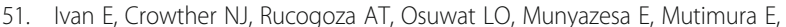
et al. Malaria and helminthic co-infection among HIV-positive pregnant women: prevalence and effects of antiretroviral therapy. Acta Trop. 2012/09/ 04. 2012;124:179-84. 
52. Zhao XF, Zhang JN, Dong HJ, Zhang T, Bian GL, Sun YW, et al. Epidemiological characteristics of malaria in Ningbo City, China 2000-2011 [Internet]. 2nd ed. Malaysia: Malaysian Society of Parasitology and Tropical Medicine (Jalan Pahang, Kuala Lumpur 50588, Malaysia); 2013. p. 267-76. Available from: http://msptm.org/files/267_-_276_Guo_Zhang_Xu.pdf

53. Lee YCA, Tang CS, Ang LW, Han HK, James L, Goh KT. Epidemiological characteristics of imported and locally-acquired malaria in Singapore. Ann Acad Med Singap. 2009;38:840-9.

54. Dev V, Phookan S, Sharma VP, Anand SP. Physiographic and entomologic risk factors of malaria in Assam, India. Am J Trop Med Hyg. 2004/11/02. 2004; $71: 451-6$

55. Zhang Y, Liu Q, Luan R, Liu X, Zhou G, Jiang J, et al. Spatial-temporal analysis of malaria and the effect of environmental factors on its incidence in Yongcheng, China, 2006-2010 [Internet]. 544th ed. UK; 2012. Available from: http://www.biomedcentral.com/1471-2458/12/544/abstract

56. Ebenezer A, Noutcha AEM, Okiwelu SN. Relationship of annual entomological inoculation rates to malaria transmission indices, Bayelsa State, Nigeria [Internet]. 1st ed. India: Malaria Research Center (E-mail: jvbd@vsnl.net); 2016. p. 46-53. Available from: http://www.nimr.org.in/ assets/531046.pdf

57. Moreno JE, Rubio-Palis Y, Paez E, Perez E, Sanchez V. Abundance, biting behaviour and parous rate of anopheline mosquito species in relation to malaria incidence in gold-mining areas of southern Venezuela. Med Vet Entomol. 2007/12/21. 2007;21:339-49.

58. Girod R, Roux E, Berger F, Stefani A, Gaborit P, Carinci R, et al. Unravelling the relationships between Anopheles darlingi (Diptera: Culicidae) densities, environmental factors and malaria incidence: understanding the variable patterns of malarial transmission in French Guiana (South America). Ann Trop Med Parasitol. 2011/03/15. 2011;105:107-22.

59. El Sayed BB, Arnot DE, Mukhtar MM, Baraka OZ, Dafalla AA, Elnaiem DE, et al. A study of the urban malaria transmission problem in Khartoum. Acta Trop. 2000/03/10. 2000;75:163-71.

60. Ye Y, Hoshen M, Kyobutungi C, Louis VR, Sauerborn R. Local scale prediction of Plasmodium falciparum malaria transmission in an endemic region using temperature and rainfall. Glob Heal Action. 2010/01/07. 2009;2.

61. Wertheim HFL, Horby P, Woodall JP. Aedes aegypti and Aedes albopictus, Atlas Hum Infect Dis. Wiley-Blackwell; 2012. p. Section 1: Infectious Disease Drivers: $33-34$

62. Salomon OD, Orellano PW, Lamfri M, Scavuzzo M, Dri L, Farace Ml, et al. Phlebotominae spatial distribution asssociated with a focus of tegumentary leishmaniasis in Las Lomitas, Formosa, Argentina, 2002. Mem Inst Oswaldo Cruz. 2006/07/25. 2006;101:295-9.

63. Thomaz Soccol V, de Castro EA, Schuhli GS e, de Carvalho Y, Marques E, de

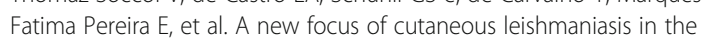
central area of Parana State, southern Brazil [Internet]. 3rd ed. Netherlands: Elsevier (P.O. Box 211, Amsterdam 1000 AE, Netherlands); 2009. p. 308-15.

64. de Camargo-Neves VLF, Spínola R, Lage L. A Leishmaniose Visceral Americana no estado de São Paulo: situação epidemiológica em 2001-2002. Rev Soc Bras Med Trop. 2003;36:27-9.

65. Uranw S, Hasker E, Roy L, Meheus F, Das ML, Bhattarai NR, et al. An outbreak investigation of visceral leishmaniasis among residents of Dharan town, eastern Nepal, evidence for urban transmission of Leishmania donovani [Internet]. 21st ed. UK; 2013. Available from: http://www.biomedcentral.com/ $1471-2334 / 13 / 21$

66. Salazar PM, Rojas G, Bucio M, Cabrera M, García G, Ruiz A, et al. Seroprevalencia de anticuerpos contra Trypanosoma cruzi y su asociación con factores de riesgo en menores de 18 años de Veracruz. México Rev Panam Salud Publica. 2007;22:75-82.

67. Medrano-Mercado N, Ugarte-Fernandez R, Butron V, Uber-Busek S, Guerra $\mathrm{HL}$, Araujo-Jorge TC, et al. Urban transmission of Chagas disease in Cochabamba, Bolivia. Mem Inst Oswaldo Cruz. 2008/09/18. 2008;103:423-30.

68. Nielsen CF, Armijos M V, Wheeler S, Carpenter TE, Boyce WM, Kelley K, et al. Risk factors associated with human infection during the 2006 West Nile virus outbreak in Davis, a residential community in northern California. Am J Trop Med Hyg. 2008/01/12. 2008;78:53-62.

69. Godsey Jr. MS, Burkhalter K, Young G, Delorey M, Smith K, Townsend J, et al. Entomologic investigations during an outbreak of West Nile virus disease in Maricopa County, Arizona, 2010. Am J Trop Med Hyg. 2012/10/31. 2012;87: 1125-31.

70. Rezza G, Nicoletti L, Angelini R, Romi R, Finarelli AC, Panning M, et al. Infection with chikungunya virus in Italy: an outbreak in a temperate region
[Internet]. 9602nd ed. UK; 2007. p. 1840-1846. Available from: https://s3. amazonaws.com/academia.edu.documents/42727896/Infection_with_ chikungunya_virus_in_Ital20160216-9308-1w1b1g6.pdf?AWSAccessKeyld= AKIAIWOWYYGZ2Y53UL3A\&Expires $=1533632155 \&$ Signature $=$ YYpBM9q9qeF4UOvquP2kpM\%2B91sA\%3D\&response-contentdisposition= inline\%3B\%20filename\%3DInfection_with_chikungunya_virus_in_Ital.pdf.

71. Ho K, Ang LW, Tan BH, Tang CS, Ooi PL, James L, et al. Epidemiology and control of chikungunya fever in Singapore [Internet]. 4th ed. United Kingdom: W.B. Saunders Ltd (32 Jamestown Road, London NW1 7BY, United Kingdom); 2011. p. 263-70. Available from: http://ovidsp.ovid.com/ovidweb. cgi?T=JS\&PAGE=reference\&D=emed13\&NEWS=N\&AN = 51319986 .

72. Vasconcelos PFC, Costa ZG, Travassos Da Rosa ES, Luna E, Rodrigues SG, Barros VLRS, et al. Epidemic of jungle yellow fever in Brazil, 2000: Implications of climatic alterations in disease spread [Internet]. 3rd ed. United States: Wiley-Liss Inc. (111 River Street, Hoboken NJ 07030-5774, United States); 2001. p. 598-604. Available from: http://citeseerx.ist.psu.edu/ viewdoc/download?doi=10.1.1.543.2170\&rep=rep1\&type=pdf.

73. Gould LH, Osman MS, Farnon EC, Griffith KS, Godsey MS, Karch S, et al. An outbreak of yellow fever with concurrent chikungunya virus transmission in South Kordofan, Sudan, 2005 [Internet]. 12th ed. Netherlands: Elsevier (P.O. Box 211, Amsterdam 1000 AE, Netherlands); 2008. p. 1247-54.

74. Carver S, Sakalidis V, Weinstein P. House mouse abundance and Ross River virus notifications in Victoria, Australia. Int J Infect Dis. 2008/05/13. 2008;12: $528-33$.

75. de Souza CE, Pinter A, Donalisio MR. Risk factors associated with the transmissionof Brazilian spotted fever in the Piracicaba river basin, state of São Paulo. Brazil Rev Soc Bras Med Trop. 2015;48:11-7.

76. Pham H V, Dang DT, Tran Minh NN, Nguyen ND, Nguyen T V. Correlates of environmental factors and human plague: an ecological study in Vietnam. Int J Epidemiol. 2009/07/09. 2009:38:1634-41.

77. Hay SI, Guerra CA, Tatem AJ, Atkinson PM, Snow RW. Urbanization, malaria transmission and disease burden in Africa. Nat Rev Microbiol. 2004/12/21. 2005;3:81-90.

78. Arunachalam N, Tana S, Espino F, Kittayapong P, Abeyewickrem W, Wai KT, Tyagi BK, Kroeger A, Sommerfeld J, Petzold M. Eco-bio-social determinants of dengue vectorbreeding: a multicountry study in urban and periurban Asia. Bull World Health Organ. 2010;88:173-84. Available from: https://www. scielosp.org/pdf/bwho/2010.v88n3/173-184/en.

79. Stoddard ST, Morrison AC, Vazquez-Prokopec GM, Soldan VP, Kochel TJ, Kitron $\mathrm{U}$, et al. The role of human movement in the transmission of vectorborne pathogens. PLoS Negl Trop Dis. 2009;3:e481.

80. World Health Organization. Joint external evaluation tool: International Health Regulations (2005) [Internet]. 2016. Available from: http://apps.who. int/iris/handle/10665/204368

81. Rodriguez-Barraquer I, Cordeiro MT, Braga C, de Souza WV, Marques ET. Cummings $\mathrm{D}$ a T. From re-emergence to hyperendemicity: the natural history of the dengue epidemic in Brazil. PLoS Negl Trop Dis. 2011;5:1-7.

82. Schwartz J, Spix C, Touloumi G, Bachárová L, Barumamdzadeh T, le Tertre A, et al. Methodological issues in studies of air pollution and daily counts of deaths or hospital admissions. J Epidemiol Community Health [Internet]. 1996 [cited 2017 Sep 14];50 Suppl 1:S3-11. Available from: https://www. ncbi.nlm.nih.gov/pmc/articles/PMC1060881/pdf/jepicomh00187-0005.pdf.
Ready to submit your research? Choose BMC and benefit from:
- fast, convenient online submission
- thorough peer review by experienced researchers in your field
- rapid publication on acceptance
- support for research data, including large and complex data types
- gold Open Access which fosters wider collaboration and increased citations
- maximum visibility for your research: over $100 \mathrm{M}$ website views per year
At BMC, research is always in progress.
Learn more biomedcentral.com/submissions 